\title{
Mancais de deslizamento: seleção correta para um projeto de máquina confiável
}

\author{
David Lira Nunez ${ }^{1}$ \\ ${ }^{1}$ Federal University of Technology - Paraná (UTFPR)
}

29 de março de 2021

Resumo: Normalmente nos cursos de Engenharia Mecânica são usados mais de um referencial teórico para o cálculo e seleção de algum elemento mecânico, visto que um autor complementa o outro. Em alguns casos esta alternância de material acadêmico, se deve a existir nesses materiais pequenas inconsistências que podem ter ocorrido durante a publicação, pela editora, de uma nova versão, ou pela falta de tópicos atualizado que acompanhem o panorama atual. Sabe-se que a Engenharia Mecânica é uma área clássica que pouco muda nos seus conceitos de base, mas os mesmos devem ser atualizados conforme o surgimento de novas tendencias, seja pelo surgimento de novos materiais, seja pelas novas formas de solucionar o modo como é feito o cálculo para a seleção correta de um elemento mecânico. Nesta publicação objetivase passar um protocolo detalhado e fácil da sequência correta e simples para a escolha de um mancal de deslizamento circular que possibilite a transmissão de energia mecânica confiável a uma máquina industrial.

\section{Introdução}

Para (Norton, 2011), mancais são por definição constituídos de duas partes em contato com movimento relativo entre si. O mancal em termos gerais, existe sempre que há duas partes móveis, onde uma delas, normalmente um eixo, se esfrega com uma camisa ao redor dela, chamado de bucha. Esses eixos normalmente são de aço, ferro fundido ou algum outro material estrutural, já as buchas normalmente são encontradas de bronze, babbitt, polímeros ou algum compósito. As buchas permitem o deslizamento confiável do eixo, seja radial ou axial e elas têm o formato cilíndrico, seja bipartido ou não.

No trabalho de (Nuñez \& Borsato, 2018), busca-se a implementação de um método que gerencie a sáude das máquinas, por meio do monitoramento dos seus elementos mecânicos, em pleno 
funcionamento, para garantir a vida útil projetada para a máquina como um todo. Nesse trabalho é usada a norma IEC 60050, que define confiabilidade como a capacidade de um elemento mecânico executar uma função conforme o necessário, sem falha, por um determinado intervalo de tempo e sob determinadas condições de operação. Nesse contexto, a confiabilidade de uma bucha pode ser comprometida por não entregar o tempo de funcionamento desejado, pela presença de uma falha ou avaria, dependendo de aspectos como: modo de operação, projeto da máquina para seleção de seus elementos mecânicos, condições ambientais, má lubrificação e falta de manutenção.

Normalmente, precisa-se de lubrificacao em qualquer mancal para reduzir o atrito e remover o calor. Os mancais podem rolar, escorregar ou fazer ambos simultaneamente. Os mancais são necessários nos mais diversos tipos de máquinas rotativas, como motores, bombas, compressores, turbinas, entre outros. Sem os mancais não seria possível a transmissão ideal do movimento e potência (Castro, 2007).

Segundo (Canzian, 2016), mancais são estruturas que suportam consideráveis cargas estáticas e dinâmicas, o correto alinhamento e posicionamento dos mancais são características essenciais para que a operação de um equipamento ocorra de maneira mais segura e eficiente, considerando que os mancais não estejam suportando esforços desnecessários e que suas características dinâmicas estejam dentros dentro das propriedades desejadas para a rotação de equipamentos.

O mancal é o elemento mecânico que tem a finalidade de suportar uma carga à qual está submetida um eixo e ao mesmo tempo possibilitar a sua rotação (Mott, 2013). Há mancais de deslizamento que também podem proporcionar o movimento linear em um eixo (Mott, 2013). porém, independentemente de haver deslizamento linear ou rotacional, preferencialmente deve haver um lubrificante entre o eixo e o mancal, e caso não seja possível isso, o material da bucha a ser escolhido deve ter propriedade de autolubrificação, condição pela qual são enquadrados como mancais com lubrificação marginal. Quando se opta por uma lubrificação entre buchas e eixos, normalmente materiais metálicos, ele passa a ser denominado de mancais com lubrificação completa, podendo ser hidrodinâmica ou hidrostática (Mott, 2013).

Quando se refere a mancais de deslizamento, existem basicamente dois tipos: de munhão ou bucha e axiais ou de escora (Juvinall \& Marshek, 2011). Neste trabalho, serão abordadas as buchas de movimento circular (rotação), que não são bipartidas, e, dentre os tipos de lubrificação serão abordados aqueles com lubrificação marginal, mista e completa hidrodinâmica. O referencial bibliográfico usado para a seleção de uma bucha que atende a uma determinada exigência de funcionamento industrial, faz parte da literatura acadêmica consolidada nos cursos de Engenharia Mecânica. 


\section{Fundamentação teórica}

\subsection{Lubrificantes}

Segundo (Norton, 2011),existem três diferentes regimes de lubrificação em um elementos de máquinas: Lubrificação Completa (que engloba Lubrificação Hidrodinâmica, Lubrificação Hidrostática e Lubrificação Elastohidrodinâmica), Lubrificação por Camada Limite e Lubrificação Parcial ou Mista.

Por um lado a lubrificacao de filme completo descreve uma situacao na qual a superficie do mancal está completamente separadas por um filme de lubrificante, eliminando qualquer contato. mas, quando a lubrificacao de contorno descreve uma situacao na qual, por razoes de geometria, aspereza da superficie, carga excessiva ou falta de lubrificante suficiente, as superficies do mancal se contatam fisicamente, podendo ocorrer desgaste por abrasao ou adesivo. Assim, pode haver uma lubrificacao de filme misto que descreve uma combinacao de filme lubrificante parcial com algumas asperezas de contato entre as superficies (eixo e bucha) (Norton, 2011).

A lubrificação hidrodinâmica ocorre quando dois elementos (bucha e eixo) sob carga, são separados por uma película relativamente contínua de lubrificante, que evita o contato direto entre eles. Nesse tipo de lubrificação há uma distribuição do fluido pela pressão criada a medida que o eixo gira constantemente, espalhando assim o lubrificante para ser posicionado em todas as superfícies de possível contato entre a bucha e o eixo sob carga. Esse tipo de lubrificação pode ser chamado também de lubrificação de película completa ou fluida (Budynas \& Nisbett, 2014).

Para (Juvinall \& Marshek, 2011), na lubrificação deve haver uma separação entre as superfícies para se poder alocar o lubrificante e criar uma película bem fina cujo valor de espessura normalmente é adotado de 0,008 a $0,020 \mathrm{~mm}$.

Por outro lado, a lubrificação estática é conseguida quando há o forçamento de água ou ar, entre a superfície de contato dos elementos (bucha e eixo) a uma determinada pressão, então neste tipo de lubrificação não ocorre a lubrificação pelo movimento de uma das superfícies do elemento em relação à outra, como acontece na lubrificação hidrodinâmica (Budynas \& Nisbett, 2014).

\subsubsection{Parâmetro de deslizamento, $\frac{\mu n}{p}$}

Para uma lubrificação completa, recomenda-se que haja uma velocidade angular considerável do eixo, com um lubrificante que tenha a viscosidade adequada para estar presente em abundância entre as partes de possível contato dos elementos (bucha e eixo), no início da partida e durante a rotação do eixo (Mott, 2013). 
A viscosidade é uma propriedade física do lubrificante e é representada pelo símbolo $\mu$. Segundo (White, 2018) este parâmetro alude às tensões locais em um fluido em movimento com uma taxa de deformação por cisalhamento do elemento de fluido. Sendo assim a viscosidade é a resistência ao cisalhamento interno do fluido, podendo variar seu valor principalmente devido à variações de temperatura e pressão, já a velocidade angular será representada por $n$, e finalmente a pressão que há na superfície carregada, é representada pelo símbolo $p$. Assim, pode ser encontrado o parâmetro de deslizamento, $\frac{\mu n}{p}$, que é adimensional (Mott, 2013).

Para o sistema internacional, neste trabalho adota-se as seguintes unidades:

$\mu$ é representada por $\mathrm{N}-\mathrm{s} / \mathrm{m}^{2}$ ou Pa-s;

$n$ é representado por rev/s;

$p$ é representado por $\mathrm{N} / \mathrm{m}^{2}$ ou $\mathrm{Pa}$.

Na Figura 1, pode ser observado o desempenho do elemento rolante (bucha), e seus tipos de lubrificação relacionados ao parâmetro de deslizamento, $\frac{\mu n}{p}$. No gráfico, quando há um coeficiente de atrito, $f$, elevado (normalmente de 0,08 a 0,14 ), e um $\frac{\mu n}{p}$ baixo, considera-se então que deva haver uma lubrificação marginal. Quando o $\frac{\mu n}{p}$, for elevado, deve ser considerada uma lubrificação completa, apresentando um coeficiente de atrito, $f$, baixo (normalmente de 0,001 a 0,05). Para valores de, $\frac{\mu n}{p}$, intermediários, deve ser usada uma lubrificação mista (Mott, 2013). 


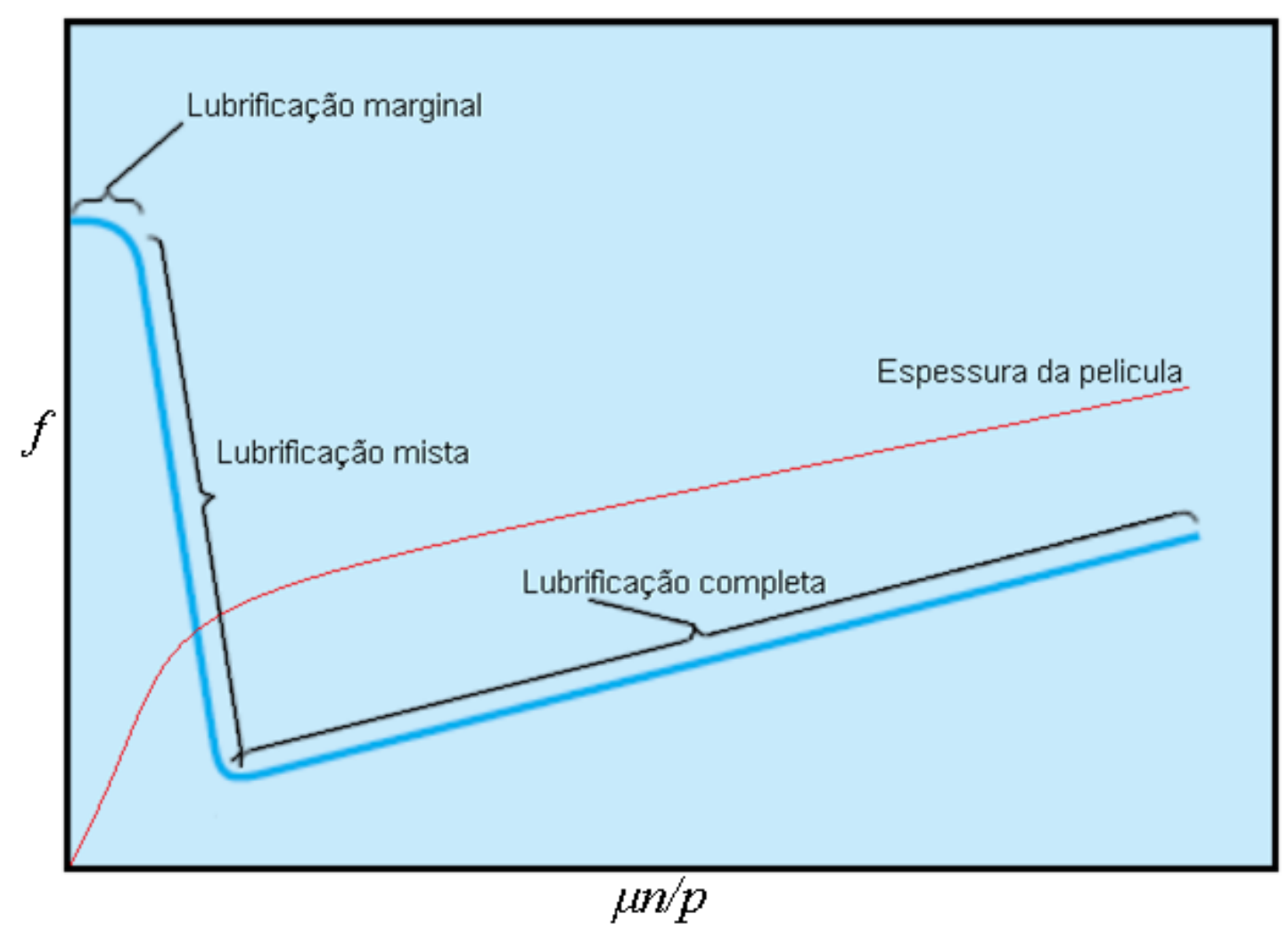

Figura 1: Desempenho do parâmetro de deslizamento (Juvinall \& Marshek, 2011)

Na Figura 1 pode ser observado, também, que quanto maior $\frac{\mu n}{p}$, maior deve ser a espessura da película do filme lubrificante. Durante o projeto, recomenda-se evitar uma lubrificação mista, por ser uma zona muito instável, conforme pode ser visto no gráfico da Figura 1, essa zona possui uma curva muito íngreme e pequenas mudanças nos seus parâmetros de deslizamento podem implicar num incorreto funcionamento (Mott, 2013).

Na lubrificação completa, alguns fatores que têm influência negativamente são: quantidade de lubrificante, adesão do lubrificante à superfície dos elementos, a qual pode depender dos seus acabamentos superficiais, materiais da bucha e eixo, e rigidez da estrutura do mancal.

Para (Juvinall \& Marshek, 2011), quanto menor a carga no mancal, menor a velocidade angular e viscosidade, para flutuar o eixo na bucha. Mas se esta rotação for muito baixa, prejudica o arrasto do lubrificante na superfície dos elementos (bucha e eixo), por menor que seja a carga. A pressão na superfície carregada, $p$, é definida pela carga radial, $W^{r}$, dividida pela área projetada da superfície do mancal, que é o diâmetro nominal interno da bucha ou diâmetro nominal do eixo, $D$, vezes o comprimento do mancal, $L$, conforme a Equação 1 .

$$
p=\frac{W^{r}}{L \cdot D}
$$




\subsubsection{Materiais para mancais de deslizamento}

Partindo da hipótese de que normalmente os eixos são de aço carbono, a bucha pode ser de:

- Babbitt a base de estanho ( $89 \% \mathrm{Sn}, 8 \% \mathrm{~Pb}$ e $3 \% \mathrm{Cu})$;

- Babbitt a base de chumbo (75\% Pb, 15\% Sb e 10\% Sn), a qual oferece boa resistência a deformação quando usados em condições de lubrificação marginal;

- Bronze fundido SAE CA932 (83\% Cu, 7\% Sn, 7\% Pb e 3\% Zn), a qual oferece boa aplicabilidade em bombas centrifugas;

- Cobre-chumbo, cobre bronze, estanho-bronze, alumínio-bronze;

- Alumínio, usado para cargas mais elevadas por apresentarem uma dureza considerável, mas em função dessa característica devem ter lubrificação completa;

- Metais porosos, fabricados a partir da metalurgia do pó de bronze, ferro e alumínio e, em alguns casos, possuem chumbo também. Estas buchas têm poros que permitem que seja inserido óleo lubrificante para que ao longo do trabalho de rotação seja liberado;

As buchas de babbitt possuem vida útil limitada pela fadiga, principalmente para temperaturas acima de $77{ }^{\circ} \mathrm{C}$, e essas não devem ser usados a temperaturas acima de $121{ }^{\circ} \mathrm{C}$ (Juvinall \& Marshek, 2011). As buchas que possuem zinco trabalham bem com pouco suprimento de lubrificante, mas elas perdem essa característica além de outras mais, quando trabalham em ambientes húmidos (Mott, 2013).

Um grande grupo de buchas é feito de polímeros que geralmente possuem propriedades autolubrificantes, podendo trabalhar a seco, apesar de ser recomendado que trabalhem com lubrificação sempre que possível. Dificilmente se deformam, mas têm pouca resistência ao desgaste. Por outro lado, sua maior característica é a resistência à corrosão. Dentro da sua composição pode haver fibra de vidro, vidro moído, fibra de carbono, pós de bronze, e alguns lubrificantes sólidos como grafite e dissulfeto de molibdênio. Alguns polímeros mais usados para bucha são (Mott, 2013):

- Politetrafluoretileno (PTFE), ou Teflon;

- Poli-imida (PA), ou nylon;

- Sulfeto de polifenileno (PPS);

- Fluoreto de polivinilideno (PVDF);

- Polieteretercetona (PEEK);

- Polieterimida (PEI);

- Polietersulfona (PES), ou polietersulfona (PESU);

- Perfluoroalcoixi (PFA) ou Teflon ${ }^{\mathrm{TM}}$. 


\subsection{Projeto de mancais de deslizamento com lubrificação marginal}

Normalmente o eixo gira ou desliza linearmente numa bucha. O projetista deve calcular qual será o material da bucha, diâmetro interno, comprimento e seu acabamento superficial. Para tal, é importante começar encontrando o produto da carga com a velocidade linear, $p V$, que é um importante parâmetro para encontrar a capacidade do material em acomodar a energia gerada pelo atrito na superfície que se desliza. Nas Tabelas 1 e 2, apresenta-se alguns polímeros com seus respectivos, $p V$, recomendados para buchas (Mott, 2013).

Segundo (Mott, 2013), para selecionar um material, o $p V$ obtido durante os cálculos deve ser multiplicado por um fator de projeto igual a 2 , e somente depois de ser utilizado para encontrar o material apropriado nas tabelas 1 e 2 . 
Tabela 1: Características das buchas de polímeros

\begin{tabular}{|c|c|c|c|c|c|}
\hline Material & $\begin{array}{l}p V \\
(\mathbf{M P a}- \\
(\mathbf{m} / \mathbf{s}))\end{array}$ & Fabricante & Descrição & $\begin{array}{l}\text { Coeficiente } \\
\text { de atrito }\end{array}$ & $\begin{array}{l}\text { Velocidade } \\
\text { máxima } \\
(\mathrm{m} / \mathbf{s})\end{array}$ \\
\hline $\begin{array}{l}\text { DTS® } 10, \\
\text { lubrifica- } \\
\text { do }\end{array}$ & 100 & $\begin{array}{l}\text { GGB Bearing } \\
\text { Technology }\end{array}$ & $\begin{array}{l}\text { Metal Polímero a base de } \\
\text { termoplástico, rugosidade } \\
\text { mínima } R a \leqslant 0,05-0,2\end{array}$ & $0,01-0,08$ & 10 \\
\hline $\begin{array}{l}\text { Vespel® } \\
\text { SP-21 }\end{array}$ & 2,19 & DuPont & $\begin{array}{l}\text { Poli-imida, reforço de } 15 \% \\
\text { de grafite; temperatura } 149 \\
{ }^{\circ} \mathrm{C}\end{array}$ & $0,12-0,24$ & - \\
\hline $\begin{array}{l}\text { Vespel® } \\
\text { SP-22 }\end{array}$ & 10,70 & DuPont & $\begin{array}{l}\text { Poli-imida, reforço de } 40 \% \\
\text { de grafite, temperatura } 393 \\
{ }^{\circ} \mathrm{C}\end{array}$ & $0,09-0,20$ & $2,54-5,08$ \\
\hline $\begin{array}{l}\text { DP11 }{ }^{T M} \text {, } \\
\text { óleo }\end{array}$ & 10,00 & $\begin{array}{l}\text { GGB Bearing } \\
\text { Technology }\end{array}$ & $\begin{array}{l}\text { Metal Polímero a base de } \\
\text { PTFE }\end{array}$ & $0,02-0,08$ & 5 \\
\hline $\begin{array}{l}\text { DP31, } \\
\text { óleo }\end{array}$ & 10,00 & $\begin{array}{l}\text { GGB Bearing } \\
\text { Technology }\end{array}$ & $\begin{array}{l}\text { Metal Polímero a base de } \\
\text { PTFE, rugosidade mínima } \\
R a \leqslant 0.05-0.4\end{array}$ & $0,01-0,05$ & 10 \\
\hline $\begin{array}{l}\text { DP4®, } \\
\text { óleo }\end{array}$ & 10,00 & $\begin{array}{l}\text { GGB Bearing } \\
\text { Technology }\end{array}$ & $\begin{array}{l}\text { Metal Polímero a base de } \\
\text { PTFE, rugosidade mínima } \\
R a \leqslant 0.05-0.4\end{array}$ & $0,02-0,08$ & 5 \\
\hline $\begin{array}{l}\text { HI-EX® } \\
10 \text {, óleo }\end{array}$ & 10,00 & $\begin{array}{l}\text { GGB Bearing } \\
\text { Technology }\end{array}$ & $\begin{array}{l}\text { Metal Polímero a base de } \\
\text { termoplástico, rugosidade } \\
\text { mínima } R a \leqslant 0,05-0,2\end{array}$ & $0,03-0,08$ & 10 \\
\hline DS, óleo & 10,00 & $\begin{array}{l}\text { GGB Bearing } \\
\text { Technology }\end{array}$ & $\begin{array}{l}\text { Metal Polímero a base de } \\
\text { termoplástico, rugosidade } \\
\text { mínima } R a \leqslant 0,4\end{array}$ & $0,03-0,08$ & 10 \\
\hline $\begin{array}{l}\text { Bronze- } \\
\text { manganês } \\
(\mathrm{C} 86200)\end{array}$ & 5,25 & $\begin{array}{l}\text { MetalTek In- } \\
\text { ternational }\end{array}$ & $\begin{array}{l}\text { SAE 430A; ASTM: B271, } \\
\text { B584, } \quad \text { B148 } \quad(65 \% \mathrm{Cu}, \\
\begin{array}{l}25 \% \mathrm{Zn}, \\
3 \% \mathrm{Mn})\end{array}\end{array}$ & - & - \\
\hline $\begin{array}{l}\mathrm{DU} \circledast, \\
\text { óleo }\end{array}$ & 5,00 & $\begin{array}{l}\text { GGB Bearing } \\
\text { Technology }\end{array}$ & $\begin{array}{l}\text { Metal Polímero a base de } \\
\text { PTFE, rugosidade mínima } \\
R a \leqslant 0,05-0,4\end{array}$ & $0,02-0,12$ & 5 \\
\hline $\begin{array}{l}\text { Bronze- } \\
\text { alumínio } \\
\text { (C95400) }\end{array}$ & 4,38 & $\begin{array}{l}\text { MetalTek In- } \\
\text { ternational }\end{array}$ & $\begin{array}{l}\text { ASTM: B271, B505, B148 } \\
(85 \% \mathrm{Cu}, 11 \% \mathrm{Al}, 4 \% \mathrm{Fe})\end{array}$ & - & - \\
\hline $\begin{array}{l}\text { Vespel }{ }^{\circledR} \\
\text { SP-221 }\end{array}$ & 3,60 & DuPont & $\begin{array}{l}\text { Poli-imida, reforço de } 15 \% \\
\text { de grafite e } 10 \% \text { PTFE; tem- } \\
\text { peratura } 260{ }^{\circ} \mathrm{C}\end{array}$ & $0,08-0,21$ & $2,54-5,08$ \\
\hline
\end{tabular}


Tabela 2: Continuação - características das buchas de polímeros

\begin{tabular}{|c|c|c|c|c|c|}
\hline Material & $\begin{array}{l}p V \\
(\mathrm{MPa}- \\
(\mathrm{m} / \mathrm{s}))\end{array}$ & Fabricante & Descrição & $\begin{array}{l}\text { Coeficiente } \\
\text { de atrito }\end{array}$ & $\begin{array}{l}\text { Velocidade } \\
\text { máxima } \\
(\mathrm{m} / \mathrm{s})\end{array}$ \\
\hline $\begin{array}{l}\mathrm{DX} \circledast 10, \\
\operatorname{graxa}\end{array}$ & 2,80 & $\begin{array}{l}\text { GGB Bearing } \\
\text { Technology }\end{array}$ & $\begin{array}{l}\text { Metal Polímero a base de termo- } \\
\text { plástico, rugosidade mínima } R a \leqslant \\
0,4\end{array}$ & $0,01-0,10$ & 2,5 \\
\hline $\begin{array}{l}\mathrm{DX} \circledast 10, \\
\text { óleo }\end{array}$ & 2,80 & $\begin{array}{l}\text { GGB Bearing } \\
\text { Technology }\end{array}$ & $\begin{array}{l}\text { Metal Polímero a base de termo- } \\
\text { plástico, rugosidade mínima } R a \leqslant \\
0,4\end{array}$ & $0,01-0,06$ & 10 \\
\hline $\begin{array}{l}\text { HI-EX® } \\
10 \text {, graxa }\end{array}$ & 2,80 & $\begin{array}{l}\text { GGB Bearing } \\
\text { Tech }\end{array}$ & $\begin{array}{l}\text { Metal Polímero a base de termo- } \\
\text { plástico, rugosidade mínima } R a \leqslant \\
0,05-0,4\end{array}$ & $0,08-0,12$ & 2,5 \\
\hline DS, graxa & 2,80 & $\begin{array}{l}\text { GGB Bearing } \\
\text { Technology }\end{array}$ & $\begin{array}{l}\text { Metal Polímero a base de termo- } \\
\text { plástico, rugosidade mínima } R a \leqslant \\
0,4\end{array}$ & $0,05-0,10$ & 2,5 \\
\hline $\begin{array}{l}\text { Bronze- } \\
\text { estanho } \\
\text { chumbado }\end{array}$ & 2,63 & $\begin{array}{l}\text { MetalTek In- } \\
\text { ternational }\end{array}$ & $\begin{array}{l}\text { SAE 67; ASTM: B271, B66, B584 } \\
(78 \% \mathrm{Cu}, 15 \% \mathrm{~Pb}, 7 \% \mathrm{Sn})\end{array}$ & - & - \\
\hline $\begin{array}{l}\mathrm{DU} \circledast \text {, se- } \\
\text { co }\end{array}$ & 1,80 & $\begin{array}{l}\text { GGB Bearing } \\
\text { Technology }\end{array}$ & $\begin{array}{l}\text { Metal Polímero a base de PTFE, ru- } \\
\text { gosidade mínima Ra } 0,3 \text { - } 0,5\end{array}$ & $0,02-0,25$ & 2,5 \\
\hline $\begin{array}{l}\text { Bronze } \\
\text { poroso }\end{array}$ & 1,75 & - & Impregnado de óleo & - & - \\
\hline DS, seco & 1,40 & $\begin{array}{l}\text { GGB Bearing } \\
\text { Technology }\end{array}$ & $\begin{array}{l}\text { Metal Polímero a base de termo- } \\
\text { plástico, rugosidade mínima } R a \leqslant \\
0,4\end{array}$ & $0,15-0,30$ & 1,5 \\
\hline Vesconite & 1,36 & Vesconite & Suporta até $120^{\circ} \mathrm{C}$ & $0,13-0,18$ & - \\
\hline $\begin{array}{l}\mathrm{DP} 11^{T M}, \\
\text { seco }\end{array}$ & 1,00 & $\begin{array}{l}\text { GGB Bearing } \\
\text { Technology }\end{array}$ & $\begin{array}{l}\text { Metal Polímero a base de PTFE, ru- } \\
\text { gosidade mínima Ra } 0,3-0,5\end{array}$ & $0.04-0.25$ & 2,5 \\
\hline $\begin{array}{l}\text { DP4®, se- } \\
\text { co }\end{array}$ & 1,00 & $\begin{array}{l}\text { GGB Bearing } \\
\text { Technology }\end{array}$ & $\begin{array}{l}\text { Metal Polímero a base de PTFE, ru- } \\
\text { gosidade mínima Ra } 0.3 \text { - } 0.5\end{array}$ & $0,04-0,25$ & 2,5 \\
\hline Graphalloy® & 0,53 & $\begin{array}{l}\text { Graphite Me- } \\
\text { tallizing }\end{array}$ & $\begin{array}{l}\text { Grafite metalizado para alta tempe- } \\
\text { raturas até } 535^{\circ} \mathrm{C}\end{array}$ & - & - \\
\hline $\begin{array}{l}\text { Rulon® } \\
641\end{array}$ & 0,35 & $\begin{array}{l}\text { SaintGobain } \\
\text { Performance } \\
\text { Plastics }\end{array}$ & Rugosidade mínima Ra 0,2 - 0,4 & - & 2 \\
\hline Rulon ${ }^{\circledR} \mathrm{J}$ & 0,26 & $\begin{array}{l}\text { SaintGobain } \\
\text { Performance } \\
\text { Plastics }\end{array}$ & $\begin{array}{l}\text { Suporta até } 315{ }^{\circ} \mathrm{C} \text {, Rugosidade } \\
\text { mínima Ra } 0,2-0,4\end{array}$ & $0,12-0,20$ & 2 \\
\hline Nylon & 0,14 & DuPont & Temperatura até $217^{\circ} \mathrm{C}$ & - & 3 \\
\hline
\end{tabular}


A velocidade linear, $V$, pode ser encontrada por meio da Equação 1, lembrando que deve ser considerada a velocidade angular, $n$, em rev/s, e o diâmetro para o uso dessa equação deve ser passado a metros, obtendo assim, uma velocidade linear em $\mathrm{m} / \mathrm{s}$.

$$
V=\pi \cdot D \cdot n
$$

Quanto a temperatura de operação, a maioria dos polímeros têm limitações, mas, geralmente os compósitos apresentam boa capacidade de trabalho a altas temperaturas. Por exemplo, um bronze-estanho e o alumínio podem operar a $260{ }^{\circ} \mathrm{C}$, já as buchas com carbono-grafite têm capacidade de operar até aproximadamente $400^{\circ} \mathrm{C}$. O PTEF também apresenta bom comportamento a temperatura elevada, conseguindo operar até $260{ }^{\circ} \mathrm{C}$ (Mott, 2013).

\subsubsection{Seleção de bucha para lubrificação marginal e rotação contínua}

Para um mancal com lubrificação marginal e rotação contínua do eixo, deve ser encontrado primeiramente o diâmetro e comprimento necessário da bucha para suportar a carga radial do eixo, normalmente o comprimento da bucha em relação ao diâmetro nominal deve ser 50\% quando trabalha a seco, $L / D=0,5$, para evitar muita área de contato. Já para buchas com lubrificação mista, recomenda-se $L / D=1$. Para buchas que têm boa capacidade em suportar temperaturas elevadas, como o carbono-grafite, pode ser usada a relação $L / D=1,5$. Assim, com essas recomendações pode ser estimado o comprimento da bucha (Mott, 2013).

A continuação é apresentado um exemplo de (Mott, 2013) para se compreender o cálculo de seleção de uma bucha.

Sabe-se que uma bucha deve ser projetada para suportar uma carga radial de $667 \mathrm{~N}$ para um eixo com diâmetro nominal de $38 \mathrm{~mm}$ que gira a $500 \mathrm{rpm}$. Pelo ambiente onde trabalha esse sistema, há a exigência que a bucha trabalhe a seco:

Como deve trabalhar a seco, considera-se o comprimento da bucha $L / D=0,5$ :

$$
L=0,5 \cdot 38=19 \mathrm{~mm}
$$

A pressão do eixo é obtida por:

$$
p=\frac{W^{r}}{L \cdot D}=\frac{667 \mathrm{~N}}{19 \mathrm{~mm} \cdot 38 \mathrm{~mm}}=0,924 \mathrm{MPa}
$$


Neste exemplo, a velocidade linear do eixo é um dado condicional de entrada que se mantem igual, independente da geometria ou material a ser selecionado para a bucha:

$$
V=\pi \cdot D \cdot n=\pi \cdot 0,038 \mathrm{~m} \cdot 8,33 \frac{\mathrm{rev}}{\mathrm{s}}=0,995 \mathrm{~m} / \mathrm{s}
$$

A seguir, encontra-se o fator, $p V$ :

$$
p V=0,924 M P a \cdot 0,994 \frac{m}{s}=0,919 M P a \cdot m / s
$$

Esse valor encontrado serve para selecionar o material da bucha, mas antes disso, deve ser multiplicado pelo fator de projeto (2,0), então o $p V$ a ser considerado é de $1,838 \mathrm{MPa}-\mathrm{m} / \mathrm{s}$. Das tabela 1 e 2, pode-se escolher o material bronze-estanho chumbado que possui um $p V$, de 2,63 $M P a-m / s$, bem acima do valor encontrado quando se trabalha a seco.

Finalmente, a folga diametral, $c_{D}$, entre a bucha e o eixo, deve ser especificada seguindo a Figura 2, onde o diâmetro nominal do eixo deve cruzar com a rotação em rpm. Dessa forma, a folga diametral mais próxima é de $50 \mu \mathrm{m}$. Independentemente do valor encontrado, deve sempre ser considerado um ajuste com folga, nunca um ajuste com interferência ou em transição. Segundo (Budynas \& Nisbett, 2014), para mancais de deslizamento as tolerâncias dimensionais recomendadas, para folga entre eixo e bucha podem ser: H8/f7 (deslizamento apertado), ou H9/d9 (deslizamento livre). 


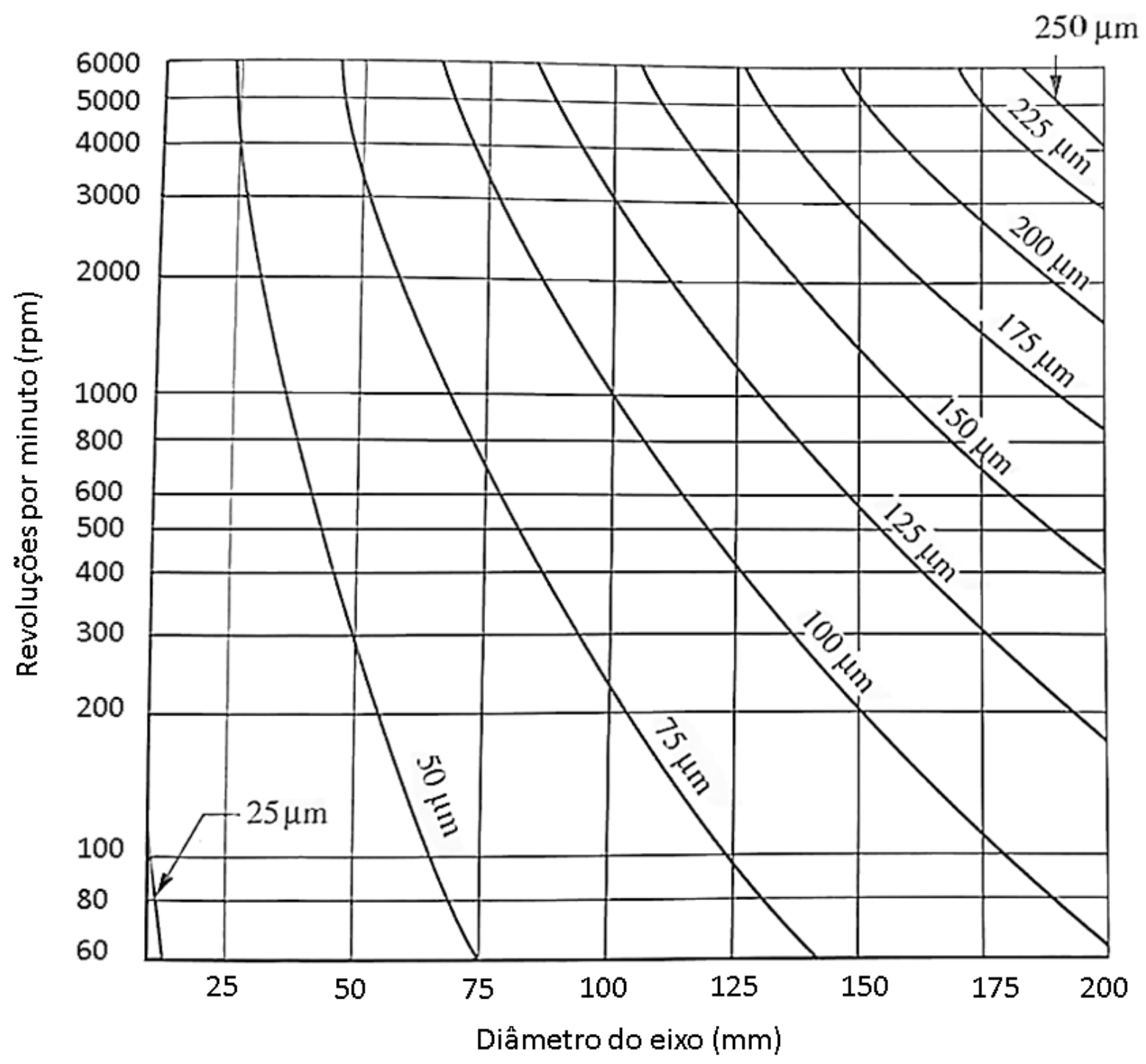

Figura 2: Folga diametral, $c_{D}$, mínima recomendada (Mott, 2013)

Para o mesmo exercício, agora não há a exigência que o mancal trabalhe a seco, sendo assim, podem ser considerados mais 3 cenários, além do primeiro já resolvido: i) comprimento mínimo de bucha a seco; ii) comprimento de bucha com lubrificação mista; e iii) comprimento para temperatura elevada. Obtendo valores respectivos apresentados na Figura 3.

\begin{tabular}{|c|c|c|c|c|c|c|c|}
\hline Magnitude & Símbolo & Valor & Unidade & Magnitude & Símbolo & Valor & Unidade \\
\hline $\begin{array}{l}\text { Comprimento máx. } \\
\text { da bucha a seco }\end{array}$ & $L$ & 19 & $\mathrm{~mm}$ & $\begin{array}{l}\text { pressão do } \\
\text { eixo }\end{array}$ & $p$ & 0,924 & Mpa \\
\hline $\begin{array}{l}\text { Comprimento mín. } \\
\text { Lubrificação mista }\end{array}$ & $L$ & 38 & $\mathrm{~mm}$ & $\begin{array}{l}\text { pressão do } \\
\text { eixo }\end{array}$ & $p$ & 0,462 & Mpa \\
\hline $\begin{array}{l}\text { Comprimento mín. } \\
\text { Temp. Elevada }\end{array}$ & $L$ & 57 & $\mathrm{~mm}$ & $\begin{array}{l}\text { pressão do } \\
\text { eixo }\end{array}$ & $p$ & 0,308 & Mpa \\
\hline
\end{tabular}

\begin{tabular}{lrr}
\hline Magnitude & Símbolo Valor \\
\hline $\begin{array}{l}\text { Fator } p V \text { com } \\
\text { fator de projeto }\end{array}$ & $p V$ & 1,838 \\
$\begin{array}{l}\text { Fator } p V \text { com } \\
\text { fator de projeto }\end{array}$ & $p V$ & 0,919 \\
$\begin{array}{l}\text { Fator } p V \text { com } \\
\text { fator de projeto }\end{array}$ & $p V$ & 0,613 \\
\hline
\end{tabular}

Figura 3: Valores encontrados para diferentes caracterisicas na bucha 
Pode ser observado na Figura 3 que quanto maior for o comprimento, $L$, da bucha, ou seja, quanto maior for o contato, menor será o fator $p V$ de projeto, que é a pressão a uma determinada velocidade linear.

Assim, para o segundo cenário, que corresponde a uma bucha que pode ter lubrificação mista, pode ser escolhido o material Bronze poroso. Finalmente, para o terceiro cenário, que é uma bucha para alta temperatura, pode ser escolhido o material $\mathrm{DP} 4^{\circledR}$ a seco, lembrando que pela teoria a bucha de PTFE suporta temperatura de até $260{ }^{\circ} \mathrm{C}$.

A seguir, para consolidar o conhecimento, apresenta-se outra aplicação mais crítica, com rotação e carga mais elevada, comparado com o primeiro exercício, mas sem diâmetro nominal do eixo estabelecido. Tem-se uma carga radial fixa de $2500 \mathrm{~N}$, e uma rotação constante de 1150 rpm, e a lubrificação deve ser marginal.

Então, se inicialmente escolhe-se um diâmetro mínimo do projeto de um eixo, $75 \mathrm{~mm}$ (por exemplo), sua pressão será de $0,889 \mathrm{MPa}$, a velocidade linear é $4,52 \mathrm{~m} / \mathrm{s}$, e seu fator, $p V$, projetado será de 8,029 $\mathrm{MPa}-\mathrm{m} / \mathrm{s}$.

Quando se aumenta o diâmetro nominal para o máximo permitido no projeto de eixo, $150 \mathrm{~mm}$ (por exemplo), a sua pressão de contato diminui para 0,222 $\mathrm{MPa}$, a velocidade linear é a mesma, e ten-se um fator, $p V$, de projeto de 4,014. Como a velocidade linear será a mesma para ambos cenários $(4,52 \mathrm{~m} / \mathrm{s})$, pode-se concluir que o fator $p V$, a ser escolhido, que por sua vez será o valor para escolher o material da bucha também diminui ao aumentar o diâmetro nominal.

Assim, segundo as tabelas 1 e 2, para um diâmetro de $75 \mathrm{~mm}$, considerando que a lubrificação deve ser marginal, não há material disponível visto que valores próximos a 8,029 $\mathrm{MPa}-\mathrm{m} / \mathrm{s}$ são buchas com lubrificação mista ou completa. E para o diâmetro de $150 \mathrm{~mm}$ o material pode ser Bronze-alumínio (C95400). Finalmente, da Figura 2, para o diâmetro de $150 \mathrm{~mm}$, a folga diametral, $c_{D}$, pode ser próxima de $150 \mu \mathrm{m}$, aproximadamente.

\subsubsection{Seleção de bucha para lubrificação marginal com rotação e carga intermitente}

Nesse tipo de aplicação, precisa se encontrar o número de ciclos equivalente, apresentado na Equação 1, em rev \min.

$$
n_{\mathrm{eq}}=\frac{n_{o} \cdot 2 \varphi}{360}, \mathrm{rev} / \min
$$

onde

$\varphi$ é o ângulo de giro, graus;

$n_{o}$ é o número de ciclos completos de giro, ciclo/min. 
Podem ser usadas as equações anteriormente apresentadas e, para a velocidade linear, a nova equação a ser usada é a velocidade linear equivalente, em $\mathrm{m} / \mathrm{s}$, representada na Equação 1.

$$
V_{\mathrm{eq}}=\pi \cdot D \cdot n_{\mathrm{eq}}
$$

Para entender melhor a sua aplicabilidade, apresenta-se o seguinte exercício adaptado de (Mott, 2013), onde se tem um eixo com diâmetro de $15 \mathrm{~mm}$ que suporta uma carga de $10200 \mathrm{~N}$ que gira $110^{\circ}$, a ciclos de 5/min. Assim, tem-se na Figura 4 os valores de entrada para selecionar o material da bucha.

\begin{tabular}{lccc}
\hline Magnitude & Símbolo & Valor & Unidade \\
\hline Carga & $W^{r}$ & 10200 & $\mathrm{~N}$ \\
Diâmetro nominal & $D$ & 15 & $\mathrm{~mm}$ \\
Ciclos de giro & $n_{0}$ & 5 & ciclo $/ \mathrm{min}$ \\
ângulo de giro & $\varphi$ & 110 & graus \\
Ciclos equivalente & $n_{e q}$ & 3,0556 & $\mathrm{rpm}$ \\
Velocidade linear equivaente & $V_{e q}$ & 0,0024 & $\mathrm{~m} / \mathrm{s}$ \\
\hline
\end{tabular}

Figura 4: Valores para encontrar uma bucha com ciclo intermitente

Finalmente, aplicando as equações anteriormente mostradas, pode-se obter os fatores de projeto, $p V$, apresentados na Figura 5.

\begin{tabular}{lcc}
\hline Magnitude & Símbolo Valor & Unidade \\
\hline $\begin{array}{l}\text { Comprimento máx. } \\
\text { da bucha a seco }\end{array}$ & $L$ & $7,5 \mathrm{~mm}$ \\
$\begin{array}{l}\text { Comprimento mín. } \\
\text { Lubrificação mista }\end{array}$ & $L$ & $15 \mathrm{~mm}$ \\
$\begin{array}{l}\text { Comprimento mín. } \\
\text { Temp. elevada }\end{array}$ & $L$ & $22,5 \mathrm{~mm}$ \\
\hline
\end{tabular}

\begin{tabular}{lccc}
\hline Magnitude & Símbolo & Valor & Unidade \\
$\begin{array}{l}\text { pressão do } \\
\text { eixo }\end{array}$ & $p$ & 90,667 & $\mathrm{MPa}$ \\
$\begin{array}{l}\text { pressão do } \\
\text { eixo }\end{array}$ & $p$ & 45,333 & $\mathrm{MPa}$ \\
$\begin{array}{l}\text { pressão do } \\
\text { eixo }\end{array}$ & $p$ & 30,222 & $\mathrm{MPa}$ \\
\hline
\end{tabular}

\begin{tabular}{lcc}
\hline Magnitude & Símbolo Valor \\
\hline $\begin{array}{l}\text { Fator } p V \text { com } \\
\text { fator de projeto }\end{array}$ & $p V$ & 0,435 \\
$\begin{array}{l}\text { Fator } p V \text { com } \\
\text { fator de projeto }\end{array}$ & $p V$ & 0,218 \\
$\begin{array}{l}\text { Fator } p V \text { com } \\
\text { fator de projeto }\end{array}$ & $p V$ & 0,145 \\
\hline
\end{tabular}

Figura 5: Fatores $p V$ para ciclo intermitente

Se acrescentamos que o sistema trabalha a temperatura de $250{ }^{\circ} \mathrm{C}$, devemos considerar que deve ser selecionada uma bucha que suporte alta temperatura, assim pode ser escolhido das tabelas 1 e 2 os seguintes materiais. DP4 ${ }^{\circledR}$, DP11 TM, DU ${ }^{\circledR}$, Vespel ${ }^{\circledR}$ SP-221 (todos trabalham a seco e acima de $250{ }^{\circ} \mathrm{C}$ ). 


\subsection{Projeto de mancais de deslizamento com lubrificação completa}

Considerando apenas lubrificação hidrodinâmica, onde a carga é suportada por um filme de lubrificação contínua. Na Figura 6 pode ser observado que conforme aumentada e se estabilizada a rotação do eixo, o lubrificante se espalha e cumpre sua função hidrodinâmica. Assim, pode ser observado na Figura 6 (a) que quando o eixo está em repouso há um comportamento de lubrificação marginal, na Figura 6 (b) no início da rotação do eixo existe o equivalente a um comportamento de lubrificação mista, e na Figura 6 (c) tem-se o comportamento de uma lubrificação hidrodinâmica completa. Na Figura 6 (c), a letra -e-representa a excentricidade que existe entre o eixo e a bucha quando o sistema alcança uma rotação de operação constante. Na Figura 6 (c) também pode ser observada a formação de uma película de lubrificação mínima, $h_{o}$. Em relação à rugosidade média, $R_{a}$, para uma boa lubrificação hidrodinâmica completa, recomenda-se valores de 40 a $80 \mu \mathrm{m}$ para equipamentos industriais, e em equipamentos de alta precisão recomenda-se $R_{a}$, de 20 a $40 \mu \mathrm{m}$ (Mott, 2013). A espessura mínima do filme lubrificante, $h_{o}$, depende do acabamento superficial dos elementos.

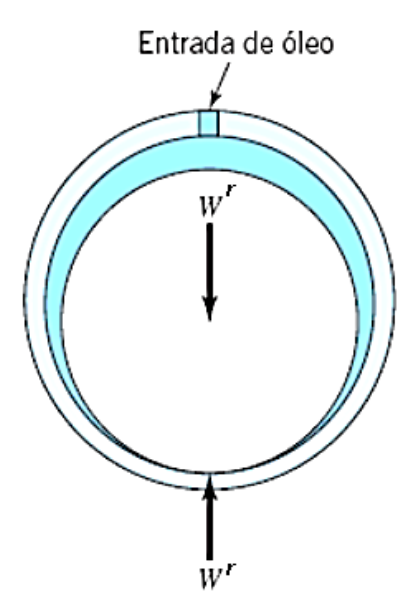

(a) Estacionário

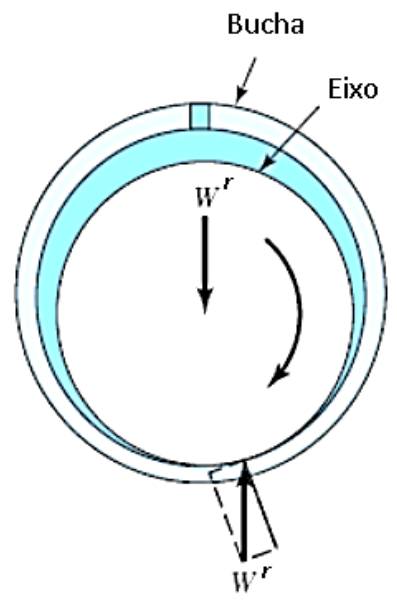

(b) Arranque (partida)

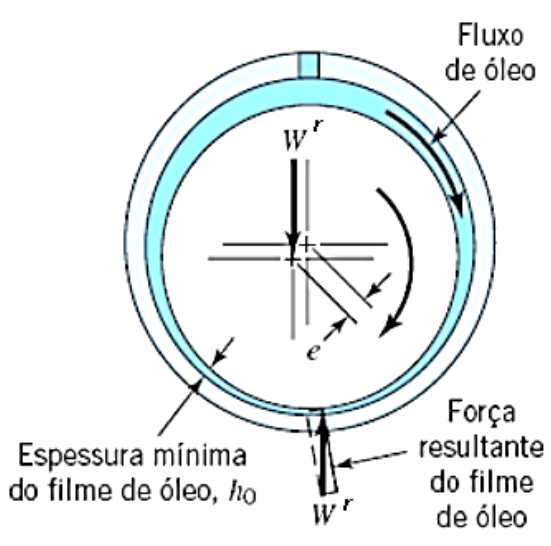

(c) Em opração (pelicula completa)

Figura 6: Deslocamento do lubrificante durante a rotação do eixo (Juvinall \& Marshek, 2011; Mott, 2013)

Para (Juvinall \& Marshek, 2011), buchas com acabamento superficial muito preciso, ou seja, que não passem de uma rugosidade de pico, $R_{P}$, de $5 \mu \mathrm{m}$ ( 0,005 $\mathrm{mm}$ ), para encontrar a espessura mínima do filme de óleo pode ser usada a Equação 1.

$$
h_{o}>0,005+0,00004 \cdot D
$$

onde $D$ é o diâmetro nominal do eixo em $\mathrm{mm}$. Porém, normalmente na indústria não há equipa- 
mento que demande tanta precisão no seu acabamento superficial, sendo assim recomenda-se utilizar, para encontrar a espessura mínima do filme, a Equação 2 (Mott, 2013).

$$
h_{o}=0,00025 \cdot D
$$

Para (Mott, 2013), na lubrificação hidrodinâmica completa há também uma relação do comprimento da bucha com o diâmetro nominal do eixo, $L / D$, de 0,25 a 1,5. Mas, pode existir projetos de mancais com valores fora dessa faixa. Já para (Juvinall \& Marshek, 2011), para buchas com lubrificação hidrodinâmica completa, podem ser considerados intervalos $L / D$ de 0,25 a 0,75 . Neste trabalho, para se usar gráficos já consolidados na literatura acadêmica, será usada a recomendação de (Mott, 2013).

\subsubsection{Temperatura de lubrificação}

Para entender a relação do lubrificante com a temperatura, é importante considerar a sua viscosidade. A viscosidade dinâmica, $\mu$, que normalmente é expressada em $\mathrm{N}-\mathrm{s} / \mathrm{m}^{2}$ ou $\mathrm{Pa}-\mathrm{s}$, mas, também pode ser encontrada numa unidade mais antiga, centipoise . Fatores de conversão muito utilizados são (Mott, 2013):

$1,0 \mathrm{~Pa} \cdot \mathrm{s}=1,0 \mathrm{~kg} /(\mathrm{m} \cdot \mathrm{s})$

1,0 reyn $=6895 \mathrm{~Pa} \cdot \mathrm{s}=6895 \mathrm{~N} \cdot\left(\mathrm{s} / \mathrm{m}^{2}\right)$

$1,0 \mathrm{~Pa} \cdot \mathrm{s}=1000$ centipoise $(\mathrm{cP})=10$ poise

A viscosidade dinâmica é a propriedade que determina o grau de resistência do fluido a uma força cisalhante, está é diretamente proporcional à força de atração entre as moléculas. Com o aumento da temperatura, essa força de atração diminui, diminuindo também a viscosidade dinâmica. A redução da viscosidade dinâmica nos líquidos devido ao aumento da temperatura é atribuída ao aumento das distâncias intermoleculares provocadas durante o aquecimento (Brunetti, 2008).

Do ponto de vista da lubrificação, o conhecimento do comportamento da viscosidade dinâmica com a temperatura é importante, pois a viscosidade dinâmica influencia consideravelmente as dimensões da espessura mínima do filme lubrificante que promove a separação das superfícies em contato (PROFITO, 2010).

Segundo (Juvinall \& Marshek, 2011), a viscosidade pode ser medida pelo tempo necessário para uma determinada quantidade de líquido escoar pelo efeito da gravidade, por meio de uma abertura padronizada. $\mathrm{O}$ aparelho que mede esse tipo de viscosidade é chamado viscosímetro universal Saybolt, mais conhecido como viscosímetro cinemático, que utiliza a razão entre a 
viscosidade absoluta dinâmica e a massa específica. Sua unidade no sistema CGS é $\mathrm{cm}^{2} / \mathrm{s}$, mas, pode ser encontrada ainda em stoke (St). Os fatores de conversão entre essas unidades são:

$1 \mathrm{St}=0,0001 \mathrm{~m}^{2} / \mathrm{s}=1 \mathrm{~cm}^{2} / \mathrm{s}$

$1 \mathrm{cSt}=0,01 \mathrm{St}=0,000001 \mathrm{~m}^{2} / \mathrm{s}=1 \mathrm{~mm}^{2} / \mathrm{s}$

Ainda (Juvinall \& Marshek, 2011), destaca a Sociedade de Engenheiros Automotivos (SAE do inglês Society of Automotive Engineers ), como a principal entidade a classificar os óleos de acordo a sua viscosidade. As propriedades da viscosidade, para a SAE, têm comportamentos diferentes dependendo da temperatura de trabalho. Por exemplo, um óleo SAE 10W, (W significa comportamento da viscosidade a temperatura baixa, que por sua vez vem do inglês Winter), mantém seu comportamento viscoso a $-25^{\circ} \mathrm{C}$, já um óleo SAE 30 (sem a letra W) significa que suas características de viscosidade se mantêm a temperaturas elevadas de até $100{ }^{\circ} \mathrm{C}$, aproximadamente. Caso haja um cenário com essa mudança de temperaturas, o recomendado é usar óleos que mantenham propriedades viscosas a frio e a quente, denominados óleos multiviscosos que para esse exemplo, seria um SAE 10W-30.

Na Figura 7 apresenta-se a classificação de viscosidade dos óleos segundo a norma SAE (J300, 2015).

\begin{tabular}{|c|c|c|c|c|c|}
\hline \multicolumn{6}{|c|}{ SAE J300 - ENGINE OILS 2015} \\
\hline \multirow{2}{*}{$\underset{\text { Grade }}{\text { SAE }}$} & \multirow{2}{*}{$\begin{array}{l}\text { Cold Cranking } \\
\text { MAX Viscosity } \\
\text { CP @Temp, }{ }^{\circ} \mathrm{C}\end{array}$} & \multirow{2}{*}{$\begin{array}{l}\text { Pumpability } \\
\text { Max Viscosity } \\
\text { CP @ Temp, }{ }^{\circ} \mathrm{C}\end{array}$} & \multicolumn{2}{|c|}{ Viscosity @ $100^{\circ} \mathrm{C}$} & \multirow{2}{*}{$\begin{array}{l}\text { HT/HS } \\
\text { @ } 150^{\circ} \mathrm{C} \\
\text { Min } \mathrm{CP}\end{array}$} \\
\hline & & & Min cSt & Max cSt & \\
\hline OW & 6200 (-35 & 60,000 @-40 & 3.8 & NA & NA \\
\hline $5 W$ & $600 @-30$ & 00 (2) -35 & & & NA \\
\hline $10 \mathrm{~W}$ & $7000 @-25$ & 60,000 @-30 & & & TNA \\
\hline $15 W$ & $7000 @-20$ & 00 (2) -25 & & & NA \\
\hline $20 W$ & 500 @ -15 & 60,000 (20 & & NA & NA \\
\hline $25 W$ & $13000 @-10$ & 60,000 (2) -15 & 9.3 & NA & NA \\
\hline 8 & NA & NA & 4.0 & $<6.1$ & 1.7 \\
\hline 12 & NA & $\mathrm{NA}$ & 5.0 & $<7.1$ & 2.0 \\
\hline 16 & NA & $\mathrm{NA}$ & 6.1 & $<8.2$ & $<2.3$ \\
\hline 20 & NA & $\mathrm{NA}$ & 6.9 & $<9.3$ & 2.6 \\
\hline 30 & NA & $\overline{N A}$ & 9.3 & $<12.5$ & 2.9 \\
\hline 40 & NA & $\overline{N A}$ & 12.5 & $<16.3$ & See note \\
\hline 50 & $\bar{N}$ & & 16.3 & $<21.9$ & 3.7 \\
\hline 60 & NA & NA & 21.9 & $<26.1$ & 3.7 \\
\hline \multicolumn{6}{|c|}{$\begin{array}{l}\text { NOTE: } 3.5 \mathrm{cP} \text { for } 0 \mathrm{~W}-40,5 W-40 \& 10 \mathrm{~W}-40 \text { grades, } 3.7 \mathrm{cP} \text { for } 15 \mathrm{~W}-40,20 \mathrm{~W}-40 \text {, } \\
25 \mathrm{~W}-40 \& 40 \text { grades. Penrite define "70" engine oils as above } 26.1 \mathrm{cSt} \text { at } 100^{\circ} \mathrm{C} \\
\& \text { "30W" as less than } 13,000 \mathrm{cP} \text { at }-5^{\circ} \mathrm{C} \text {. }\end{array}$} \\
\hline
\end{tabular}

Figura 7: Classificação SAE para óleo lubrificante

Na Figura 7, a viscosidade absoluta é medida em centipoise $(c P)$, a partir da qual, caso 
necessário, obtém-se a viscosidade cinemática em centistokes $(\mathrm{cSt})$, dividindo-a pela massa específica do óleo. Para os óleos derivados de petróleo, a massa específica é de $890 \mathrm{~kg} / \mathrm{m}^{3}$ a uma temperatura e $15,6^{\circ} \mathrm{C}$. Para outras temperaturas de trabalho, a densidade do óleo pode ser encontrada Equação 2 (Juvinall \& Marshek, 2011).

$$
\rho=890-0,63(x-15,6)
$$

Quando não há necessidade de um óleo multiviscoso, ou seja, que não tem valores de viscosidade que se modifiquem bruscamente com a variação de temperatura, cenário que costuma-se encontrar na indústria, pode ser usada a Figura 8 onde, dependendo da temperatura de trabalho e da viscosidade absoluta, pode ser encontrada a classe de óleo lubrificante segundo a SAE. 


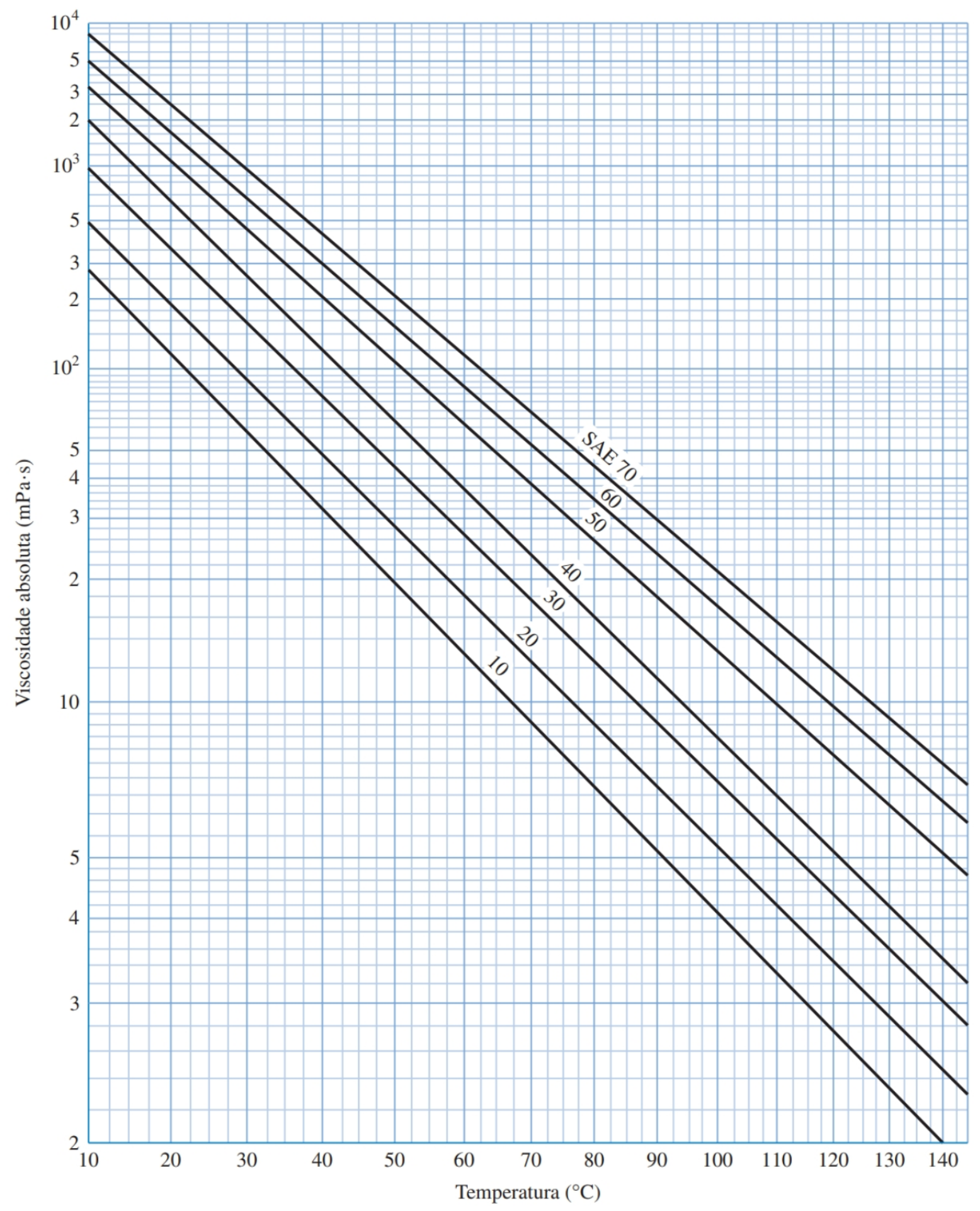

Figura 8: Gráfico de viscosidade \& temperatura (Budynas \& Nisbett, 2014)

\subsubsection{Número de Sommerfeld, $S$}

O funcionamento de um mancal com lubrificação hidrodinâmica completa pode ser caracterizada pela variável adimensional de Sommerfeld, $S$, também chamada de "número carac- 
terístico do mancal” definido na Equação 2 (Mott, 2013; Juvinall \& Marshek, 2011).

$$
S=\frac{\mu \cdot n}{p} \cdot\left(\frac{R}{c}\right)^{2}
$$

onde $R$, é o raio nominal do eixo e $c$, é a folga radial entre eixo e bucha, que pode ser obtido ao dividir por 2, o $c_{D}$, da Figura 2, esses valores estão em $m m$. Na Figura 9 é apresentada uma imagem que auxilia a entender onde podem ser encontradas as variáveis a serem usada para encontrar o número característico do mancal, $S$.

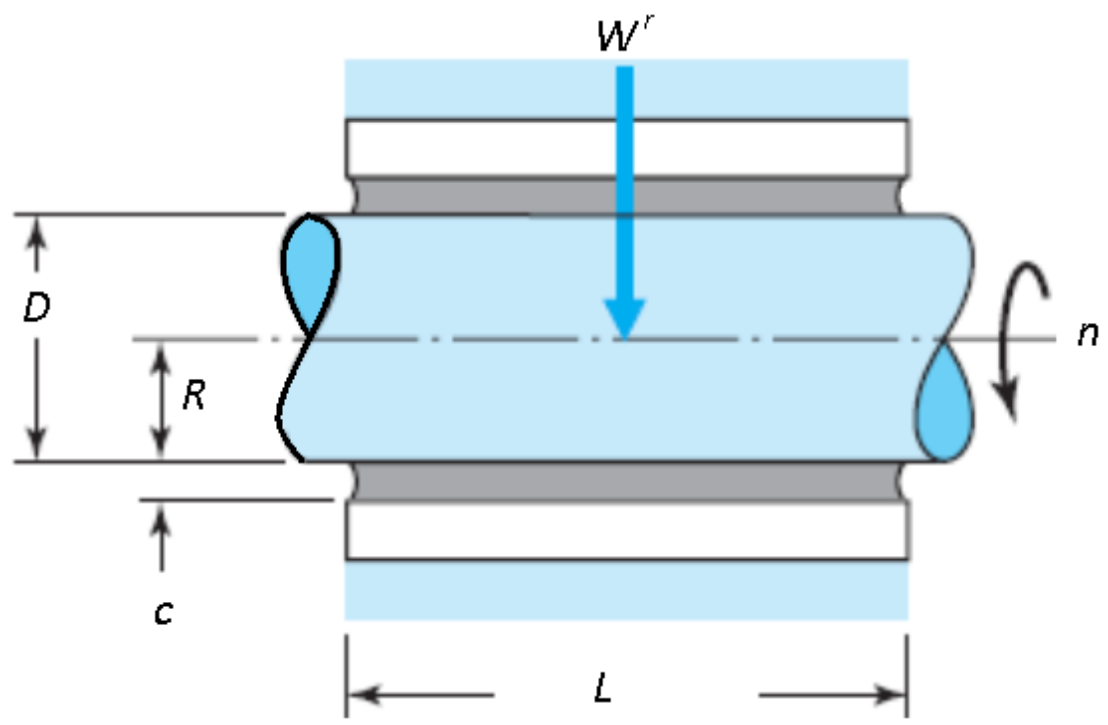

Figura 9: Variáveis para o número característico do mancal (Juvinall \& Marshek, 2011)

Para encontrar o $S$ na fase de projeto de mancal com lubrificação completa, é necessário encontrar a relação da espessura mínima de película com a folga radial, $h_{o} / c$ e, dessa forma, é possível usar o gráfico da Figura 10 que apresenta no eixo x o número característico do mancal, $S$, e no eixo y a variável da espessura mínima de filme, $h_{o} / c$, além da taxa de excentricidade, $\epsilon=\frac{e}{c}(\mathrm{Bu}-$ dynas \& Nisbett, 2014). Nesse gráfico pode ser escolhida uma das curvas que têm a relação de diâmetro nominal e comprimento da bucha $L / D$. As linhas tracejadas na Figura 10 representam fronteiras recomendadas para a carga máxima, $W$, e o coeficiente mínimo de atrito, $f$. 


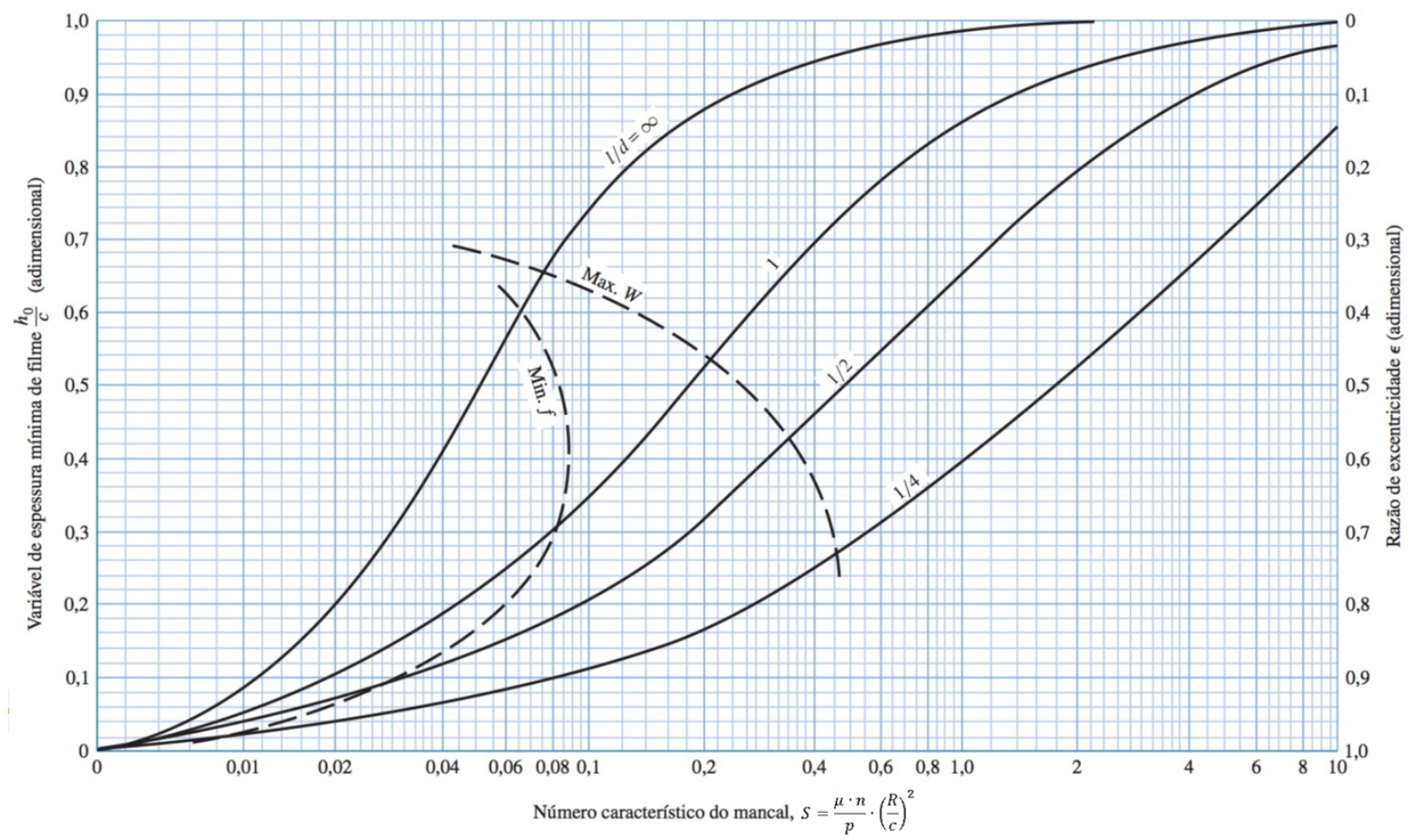

Figura 10: Variáveis da película mínima em função do número característico do mancal (Budynas \& Nisbett, 2014)

A espessura mínima de filme, $h_{o}$, é encontrada seguindo Equação 2 recomendada por (Mott, 2013). Tendo-se esse valor, pode ser encontrado o número característico do mancal, $S$. Essa espessura mínima ocorre a uma determinada posição angular de rotação do eixo, $\phi$, conforme pode ser observado na Figura 11. 


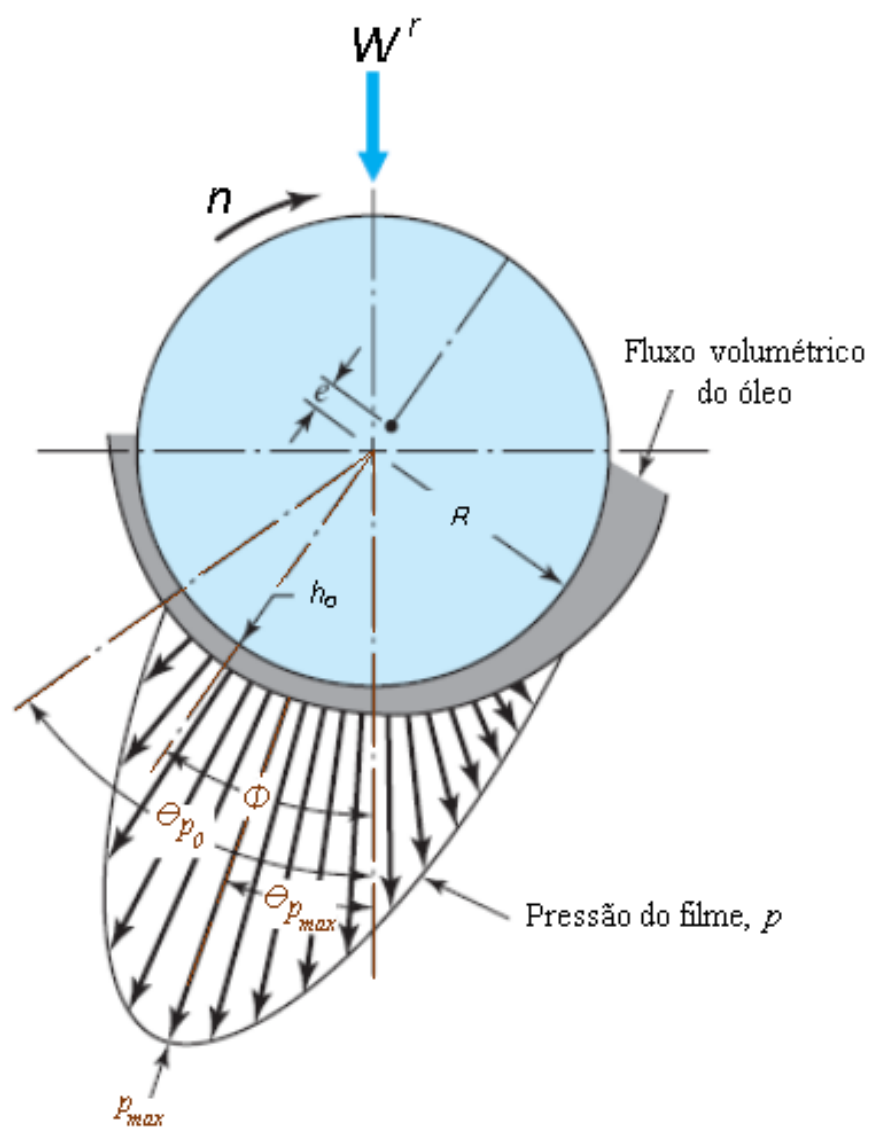

Figura 11: Distribuição de pressão de filme lubrificante (Juvinall \& Marshek, 2011)

Dessa forma, para encontrar essa posição mínima de filme, em graus, deve ser usada o gráfico da Figura 12, uma vez que já se sabe o valor do número característico do mancal, $S$, e sabendo a relação do mancal entre comprimento e diâmetro, L/D (Juvinall \& Marshek, 2011). 


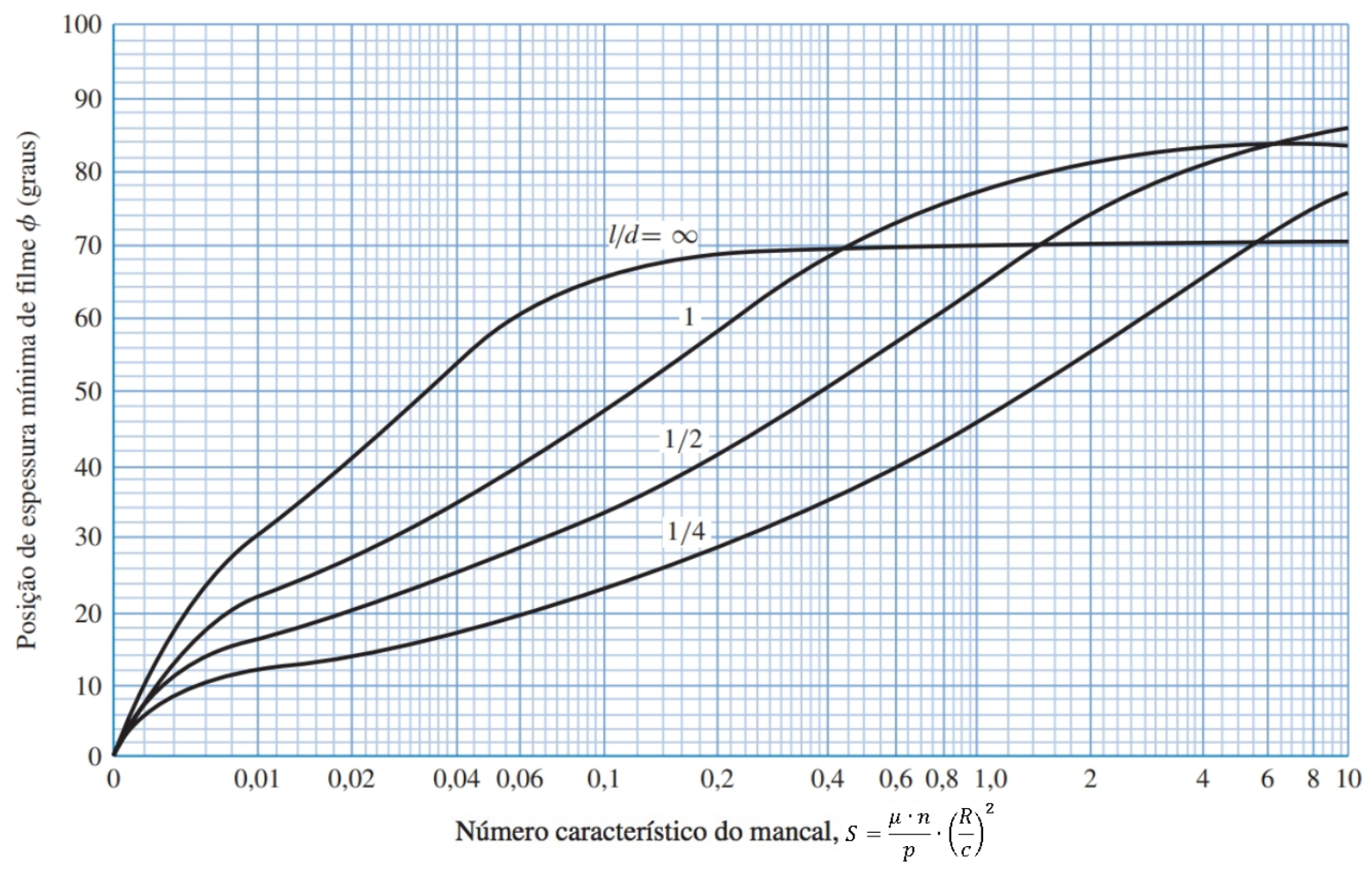

Figura 12: Posição de espessura mínima de filme lubrificante (Budynas \& Nisbett, 2014)

A pressão estática de uma lubrificação completa, também, pode ser encontrada usando Equação 1. A mesma que é usada para lubrificação marginal: $p=W^{r} /(L \cdot D)$.

Nesse contexto, durante a operação do sistema, ou seja, com a rotação do eixo, é espalhado o lubrificante produzindo uma pressão máxima, que pode ser encontrada usando o gráfico da Figura 13. 


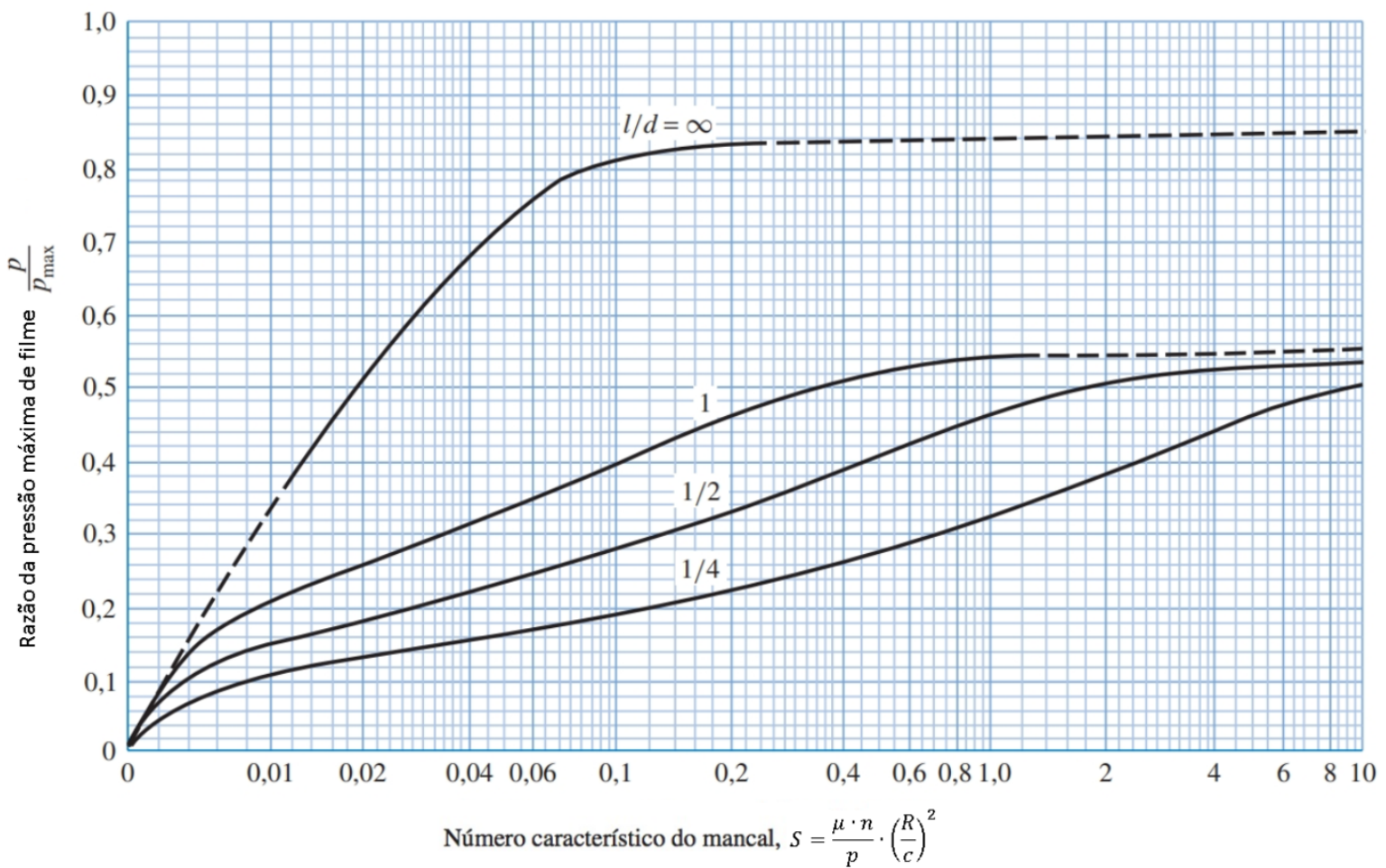

Figura 13: Razão de pressão máxima (Budynas \& Nisbett, 2014)

Também podem ser encontradas as posições angulares, tanto da pressão máxima como do término de pressão, usando o gráfico da Figura 14. Observe-se que nesse gráfico, as linhas com círculos cheios são usadas para encontrar a posição angular da pressão máxima. Já as linhas com círculos vazados, são para encontrar a posição angular do término de pressão (Budynas \& Nisbett, 2014). 


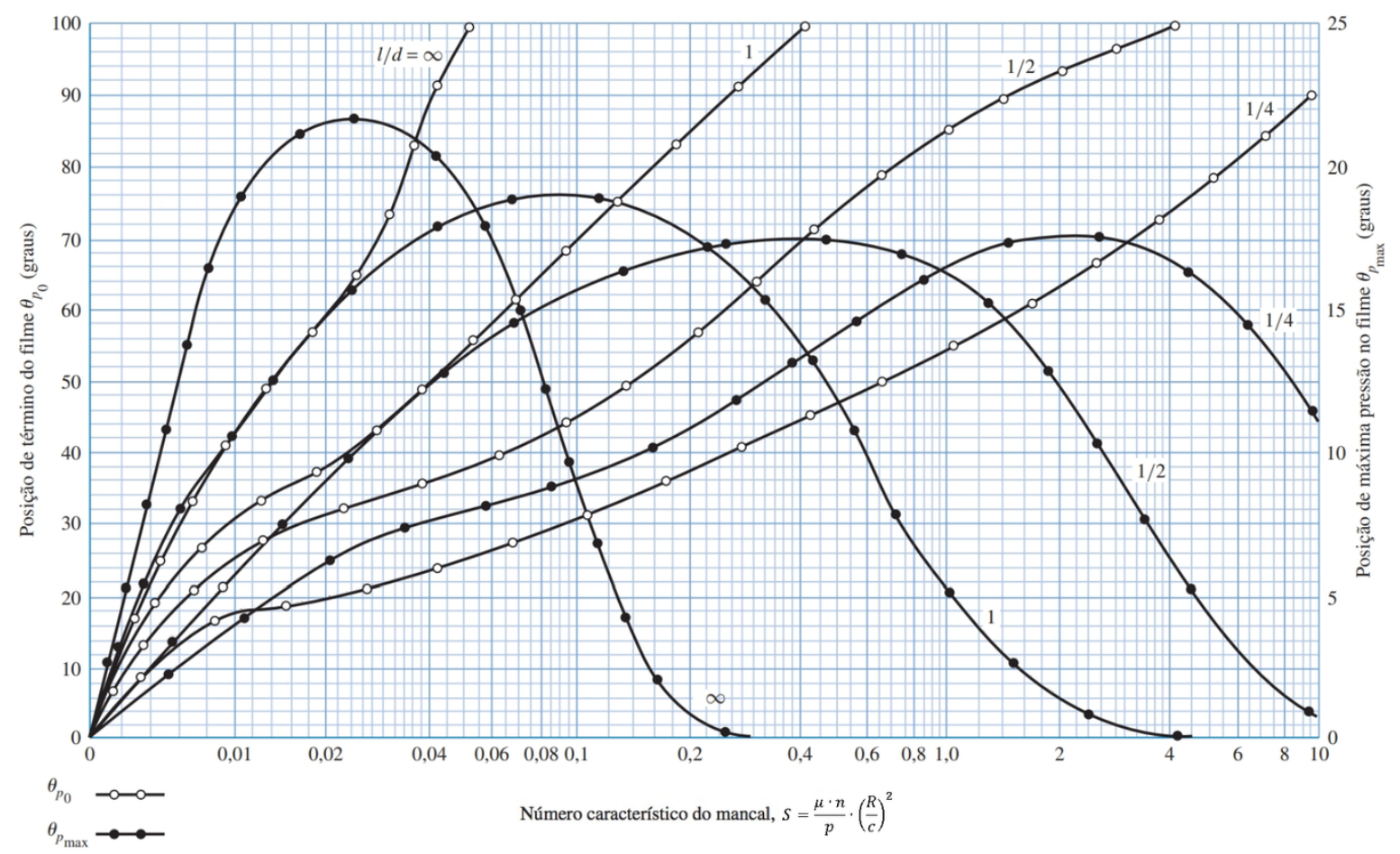

Figura 14: Posição angular da pressão do lubrificante (Budynas \& Nisbett, 2014)

No projeto de mancal de deslizamento, também pode ser determinada a quantidade de óleo, em um determinado intervalo de tempo, que fica circulando na superfície da bucha durante sua operação com o eixo, ou seja, o fluxo volumétrico do lubrificante, $Q$. Para encontrar essa variável, deve ser usado o gráfico da Figura 15, entrando com o valor de número característicos do mancal, $S$, e a relação do comprimento com o diâmetro do mancal $L / D$ (Juvinall \& Marshek, 2011). 


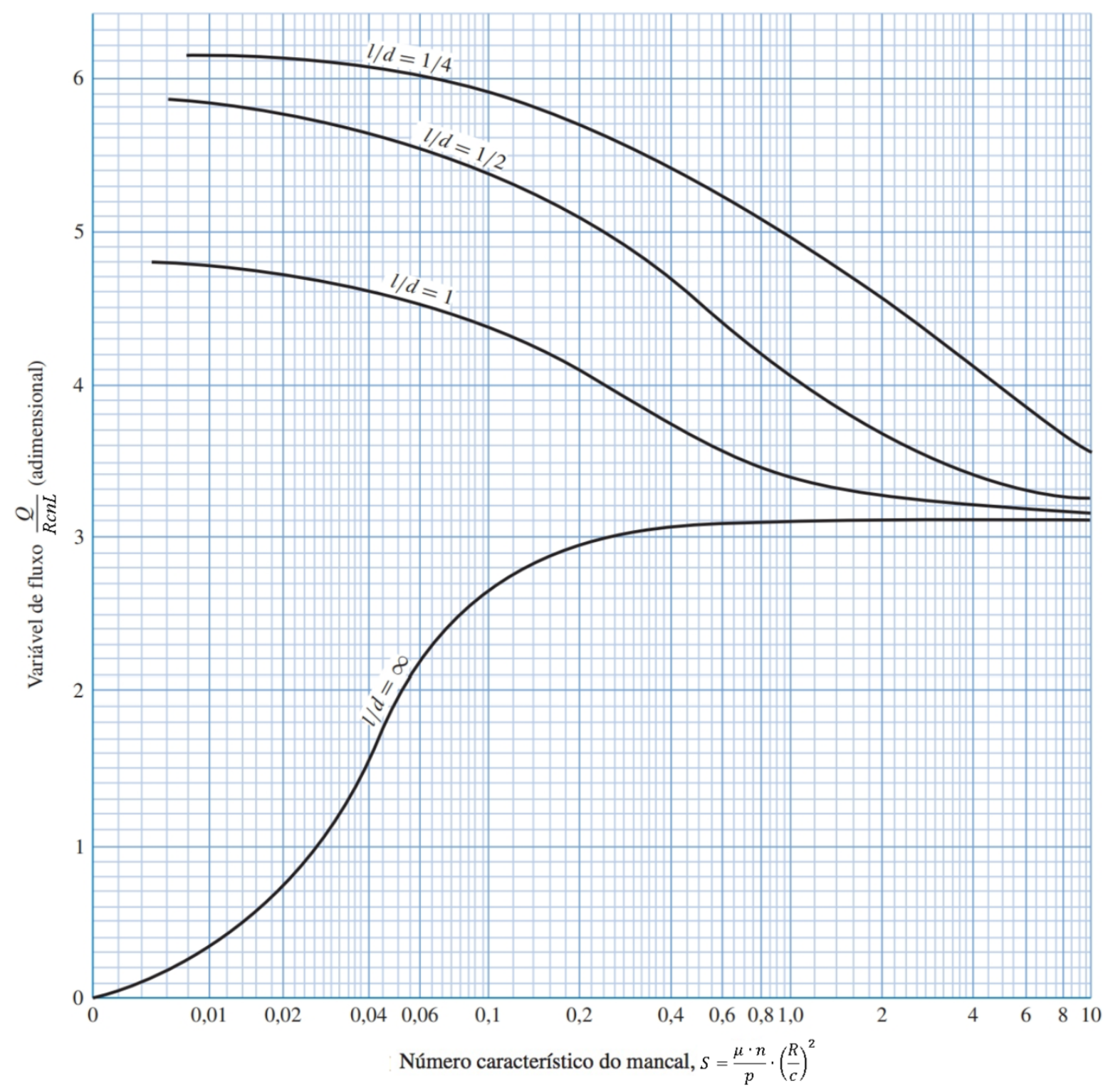

Figura 15: Relação número característico do mancal e variável fluxo (Budynas \& Nisbett, 2014)

Esse fluxo volumétrico, pela ação da rotação do eixo e consequente espalhamento do lubrificante na superfície da bucha, gera um vazamento do óleo nas suas laterais chamado de fluxo de saída, $Q_{s}$. Essa perda deve ser calculada para projetar a quantidade de lubrificante a ser acrescentado durante a operação da máquina. Par tal, deve ser encontrada, no gráfico da Figura 16, a razão de fluxo $Q_{s} / Q$. E, para encontrar dita variável deve ser ingressada a relação, $L / D$, e o número característico do mancal, $S$ (Juvinall \& Marshek, 2011). 


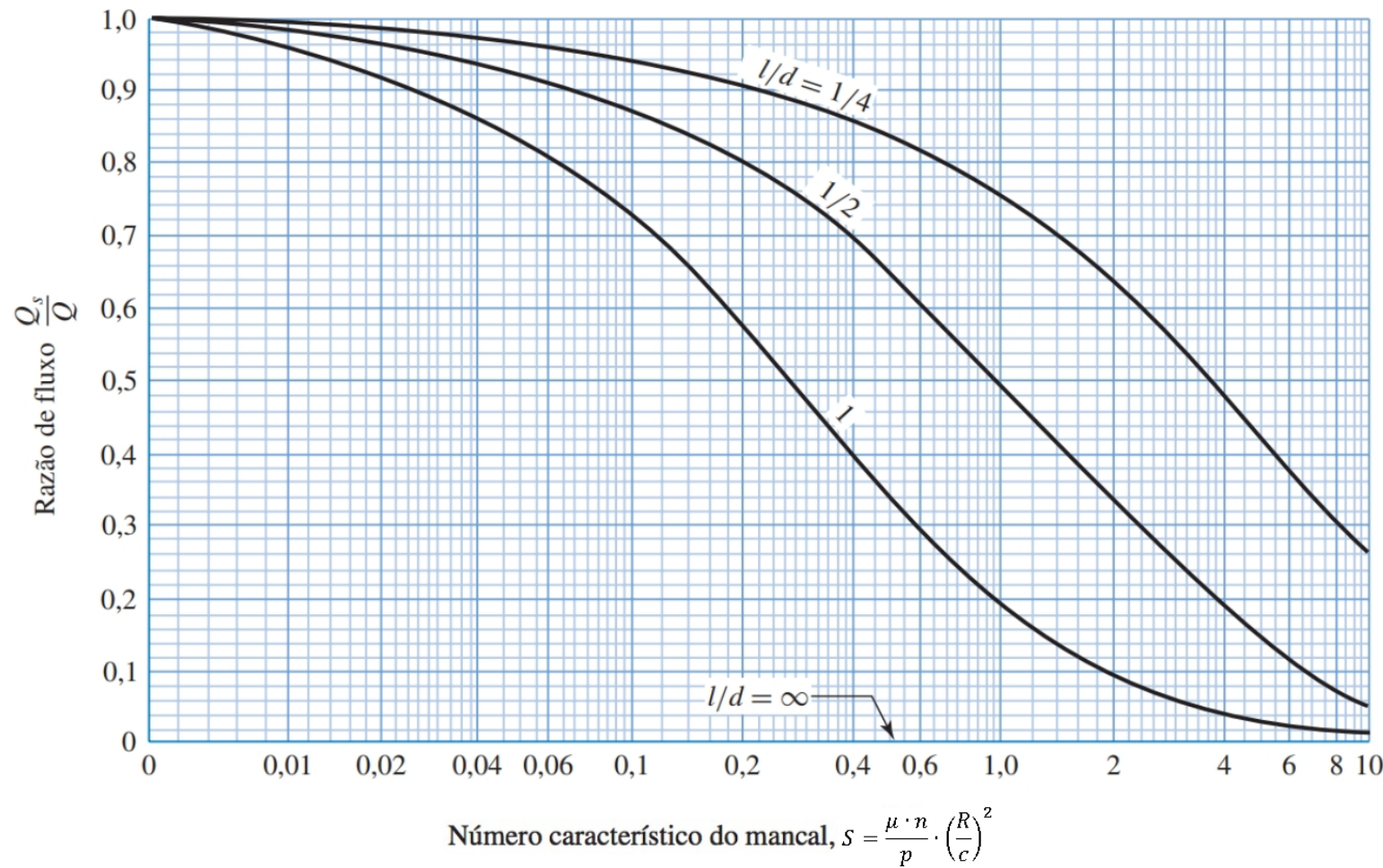

Figura 16: Razão do fluxo de saída e fluxo de operção (Budynas \& Nisbett, 2014)

Para (Mott, 2013), o número característico do mancal, $S$, também pode ser relacionado com a variável do coeficiente de atrito apresentado na Figura 17, que se encontra em relação ao raio e a folga radial do eixo e bucha, $f(R / c)$, da mesma forma que na maioria dos gráficos, deve ser usada uma das curvas que possuem a relação de diâmetro nominal e comprimento da bucha, $L / D$, e o número característico do mancal, $S$. 


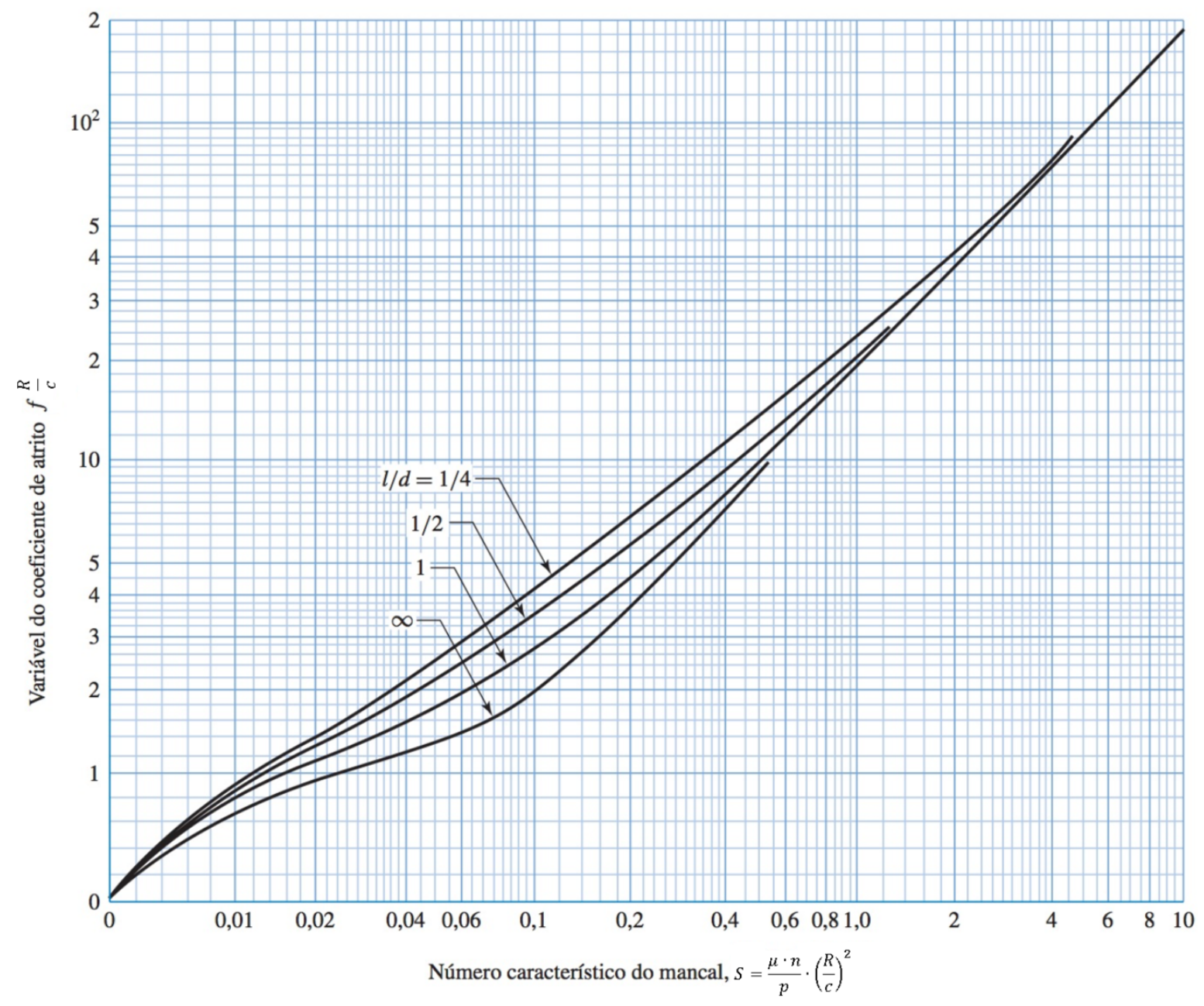

Figura 17: Variável de coeficiente de atrito em função do número de Sommerfeld (Budynas \& Nisbett, 2014)

A seguir é reproduzido um exercício proposto por (Mott, 2013), para entender melhor a sequência do projeto de seleção de uma bucha com lubrificação completa, além de acrescentar mais algumas equações importantes a serem consideradas neste tipo de cálculo.

Uma carga radial constante de $6670 \mathrm{~N}$ de um eixo que gira a $850 \mathrm{rpm}$, tem um diâmetro nominal de $63,5 \mathrm{~mm}$ e deve trabalhar a $71{ }^{\circ} \mathrm{C}$.

Considera-se a relação $L / D=1$, da Figura 2, ingressando o diâmetro do eixo e a sua rotação, será encontrada a folga diametral, $c_{D}$, esse valor encontrado é dividido por 2 para encontrar a folga rial, $c$. Na sequência deve ser encontrada a espessura mínima de filme do lubrificante, $h_{o}$, usando a Equação 2, para que possa assim ser encontrada a variável de espessura mínima de filme, $h_{o} / c$, que por sua vez servira para encontrar o número característico do mancal, $S$, no gráfico da Figura 10. Importante destacar que tendo encontrado o $S$ e sabendo a relação $L / D$, valores fundamentais no projeto de uma bucha, na sequência usando esses dois valores poderão 
ser encontradas mais variáveis para o projeto.

Assim, obtendo o $S$, e sabendo a relação $L / D$, agora pode ser encontrado no gráfico da Figura 12, a posição angular onde ocorre a espessura mínima do lubrificante. Na Figura 18 são apresentados os valores obtido até o momento. Lembrando a recomendação de (Juvinall \& Marshek, 2011), onde define que a espessura do óleo lubrificante deve estar no intervalo de 0,008 a 0,02 , pode ser observado que a espessura encontrada de 0,016 está dentro do intervalo recomendado pela literatura. Além disso, também apresenta-se a velocidade linear à qual é submetida a superfície da bucha, embora esse valor não será usado no decorrer do projeto, mas é importante conhecê-lo.

\begin{tabular}{lccc}
\hline Magnitude & Símbolo & Valor & Unidade \\
\hline Carga & $W^{r}$ & 6670 & $\mathrm{~N}$ \\
Diâmetro nominal & $D$ & 63,5 & $\mathrm{~mm}$ \\
Rotação & $n$ & 850 & $\mathrm{rpm}$ \\
Temperatura de trabalho & $T$ & 71 & ${ }^{\circ} \mathrm{C}$ \\
Velocidade linear & $V$ & 2,83 & $\mathrm{~m} / \mathrm{s}$ \\
\hline Comprimento máx. (L/D $=1)$ & $L$ & 63,5 & $\mathrm{~mm}$ \\
Ingressar da Fig. 2 a folga radial & $c$ & 0,0375 & $\mathrm{~mm}$ \\
Espessura mínima da película de filme & $h_{\circ}$ & 0,016 & $\mathrm{~mm}$ \\
Variável espessura mín. de filme & $h_{0} / c$ & 0,42 & - \\
Ingressar da Fig. 10 o núm. ctco. do mancal & $\mathrm{S}$ & 0,1365 & - \\
Posição do filme mínimo - Fig. 12 & $\Phi$ & 52 & ${ }^{\circ}$ \\
\hline
\end{tabular}

Figura 18: Valores para encontrar o número característico do mancal

Tendo encontrado o valor do $S$, na sequência pode ser usada a Equação 2, mas, representada em função da viscosidade dinâmica, tendo assim a Equação 2, que agora precisa do valor da pressão gerada pela carga radial do eixo na superfície carregada, $p$, que pode ser encontrada usando a Equação 1.

$$
\mu=\frac{S \cdot p}{n} \cdot\left(\frac{c}{R}\right)^{2}
$$

Da Equação 2, obtém-se o valor para a viscosidade dinâmica em $M P a-s$. A unidade a ser usada dependendo do gráfico ao qual se tem disponibilidade. Nesta publicação usa-se o gráfico da Figura 8 que está em $m P a-s$, ou seja, deve ocorrer uma conversão de unidades. Assim, ingressando nesse gráfico a temperatura de operação exigida e a viscosidade dinâmica encontrada em $m P a-s$, pode ser selecionado o óleo lubrificante SAE 40. Também pode ser calculada a pressão máxima de operação, posição angular dessa pressão máxima, e a posição angular do 
término de pressão, na Figura 13 e Figura 14, respectivamente. Na Figura 19 apresentam-se os valores obtidos para encontrar a viscosidade dinâmica.

\begin{tabular}{lccc}
\hline Magnitude & Símbolo & Valor & Unidade \\
Pressão estática do eixo & $p$ & 1,65 & $\mathrm{MPa}$ \\
& $\mu$ & 0,000000022 & $\mathrm{MPa}-\mathrm{s}$ \\
Viscosidade dinâmica absoluta & $\mu$ & 0,022 & $\mathrm{~Pa}-\mathrm{s}$ \\
& $\mu$ & 22,2 & $\mathrm{mPa}-\mathrm{s}$ \\
Escolha de lubrificante SAE - Fig. 8 & $\mu$ & 0,022 & $\mathrm{~kg} /(\mathrm{m}-\mathrm{s})$ \\
Razão da pressão máxima - Fig. 13 & $p / p_{\max }$ & Próximo de SAE 40 & \\
Pressão máxima & $p_{\max }$ & 3,87 & $\mathrm{MPa}$ \\
Posição angular da pressão máxima - Fig. 14 & $\theta p_{\max }$ & 18,5 & $\circ$ \\
Posição angular da pressão zero - Fig. 14 & $\theta p_{0}$ & 76,5 & $\circ$ \\
\hline
\end{tabular}

Figura 19: Valores de pressão para selecionar o tipo de óleo

Também pode ser calculado o fluxo volumétrico, $Q$, a partir da Figura 15, ingressando $S$ e $L / D$. Além disso, pode ser encontrado, usando a Figura 16, o fluxo volumétrico de saída, ou seja, a quantidade de óleo que vaza pelas laterais da bucha durante sua operação, num determinado intervalo de tempo. Na Figura 20 apresentam-se os valores obtidos para fluxo volumétrico.

\begin{tabular}{lccc} 
Magnitude & Símbolo & Valor & Unidade \\
Ingressar a variável de fluxo - Fig. 15 & $Q / R \mathrm{cnL}$ & 4,27 & - \\
Fluxo volumétrico & $Q$ & 274407,2133 & $\mathrm{~mm}^{3} / \mathrm{min}$ \\
& $Q$ & 4,57 & $\mathrm{~cm}^{3} / \mathrm{s}$ \\
\hline Ingressar razão de fluxo - Fig 16 & $Q_{s} / Q$ & 0,667 & - \\
Fluxo de saída & $Q_{s}$ & 3,05 & $\mathrm{~cm}^{3} / \mathrm{s}$ \\
\hline
\end{tabular}

Figura 20: Valores de fluxo volumétrico

Agora deve ser encontrado o coeficiente de atrito com auxílio do gráfico da Figura 17. Para tal, tendo o $S$, e sabendo a relação $L / D$, pode ser encontrada a variável de coeficiente de atrito, $f(R / c)$. Na sequência, encontrando a relação, $R / c$, pode ser encontrado o coeficiente de atrito, $f$, que neste caso é 0,004. Lembrando a recomendação de (Mott, 2013), onde se define que na lubrificação completa o coeficiente de atrito deve estar no intervalo de 0,001 a 0,05, então, o valor encontrado atende esta recomendação. Além disso, o mesmo autor recomenda que as superfícies de contato devem ter uma rugosidade média, Ra, de 40 a $80 \mu \mathrm{m}$.

Continuando, com o coeficiente de atrito pode ser encontrado o torque de fricção, $T_{f}$, usando a 
Equação 2.

$$
T_{f}=f \cdot W^{r} \cdot R
$$

onde, o coeficiente de atrito é adimensional, a carga radial, $W^{r}$, deve estar em $N$ e o raio, $R$, deve estar em $m$. Desta forma, tendo o torque de fricção, $T_{f}$, pode ser usado para encontrar a perda de energia por atrito, $P_{f}$, usando a Equação 2.

$$
P_{f}=\frac{T_{f} \cdot n}{9,55}
$$

Observe que para um toque em $N$ - $m$, e uma rotação em $r p m$, há necessidade de se dividir o produto deles por 9,55, que é um fator de correção para que a perda de energia por atrito, $P_{f}$, seja em Watts $(W)$. Na Figura 21 são apresentados os valores relacionados ao coeficiente de atrito, $f$.

\begin{tabular}{lccc} 
Magnitude & Símbolo & Valor & Unidade \\
\hline Ingressar da Fig-17 a variável de atrito & $f(R / c)$ & 3,4 & - \\
Relação raio folga & $\mathrm{R} / \mathrm{c}$ & 846,67 & - \\
Coeficiente de atrito & $f$ & 0,004 & \\
Torque de ficção & $T_{f}$ & 0,850 & $\mathrm{~N}-\mathrm{m}$ \\
Perda de energia de atrito & $P_{f}$ & 75,69 & $\mathrm{~W}$ \\
\hline
\end{tabular}

Figura 21: Valores para encontrar valores de atrito

Neste exemplo, a perda de energia de 75,69 $\mathrm{W}$ corresponde a taxa de entrada de energia ao lubrificante dentro da bucha, que poderia elevar a temperatura caso não existisse óleo ou fosse selecionado um lubrificante de forma incorreta.

\subsubsection{Suprimento de óleo}

Para (Mott, 2013), o suprimento para que a lubrificação alcance efetivamente a superfície de deslizamento dos elementos bucha e eixo, deve ocorrer sempre a partir de uma área oposta ao local de pressão hidrodinâmica que sustenta a carga. Ranhuras são frequentemente usadas para distribuir o óleo ao longo do comprimento da bucha, $L$, conforme é apresentado na Figura 22. É importante garantir o efetivo funcionamento do mancal com a presença do lubrificante, já que este cumpre funções de reduzir o atrito além de dissipar o calor nos mancais. 


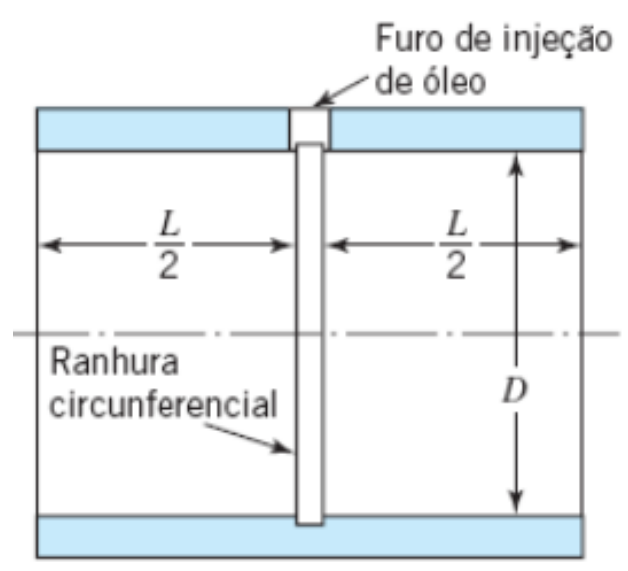

a) ranhura circunferencial

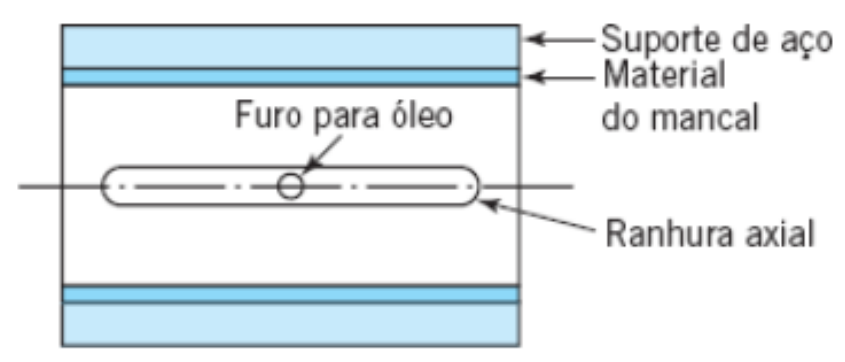

b) ranhura axial

Figura 22: Formatos mais comuns de ranhura para buchas (Juvinall \& Marshek, 2011)

Para o óleo a ser especificado para um mancal de deslizamento, há diversos fornecedores que oferecem uma grande variedade de categorias, normalmente divididas em óleos minerais derivados de petróleo natural refinado, e sintéticos. A grosso modo, os minerais têm menor custo e maior margem de aplicabilidade, e aditivos são frequentemente acrescentados para melhorar sua viscosidade, e reduzir sua oxidação e outra forma de degradação química. Já os sintéticos são formulações químicas criados para aplicações específicas, tem custo superior, comparado aos minerais, já que são mais eficientes.

Nesta publicação usou-se a classificação de óleos segundo a SAE, mas existem outras entidades que classificam o óleo, tais como a: Organização Internacional para Padronização (ISO - do inglês International Organization for Standardization), e a AGMA (do inglês American Gear Manufacturers Association ). Na Figura 23 é apresentada uma carta com as equivalências das classes de óleo lubrificantes entre estas normas. 


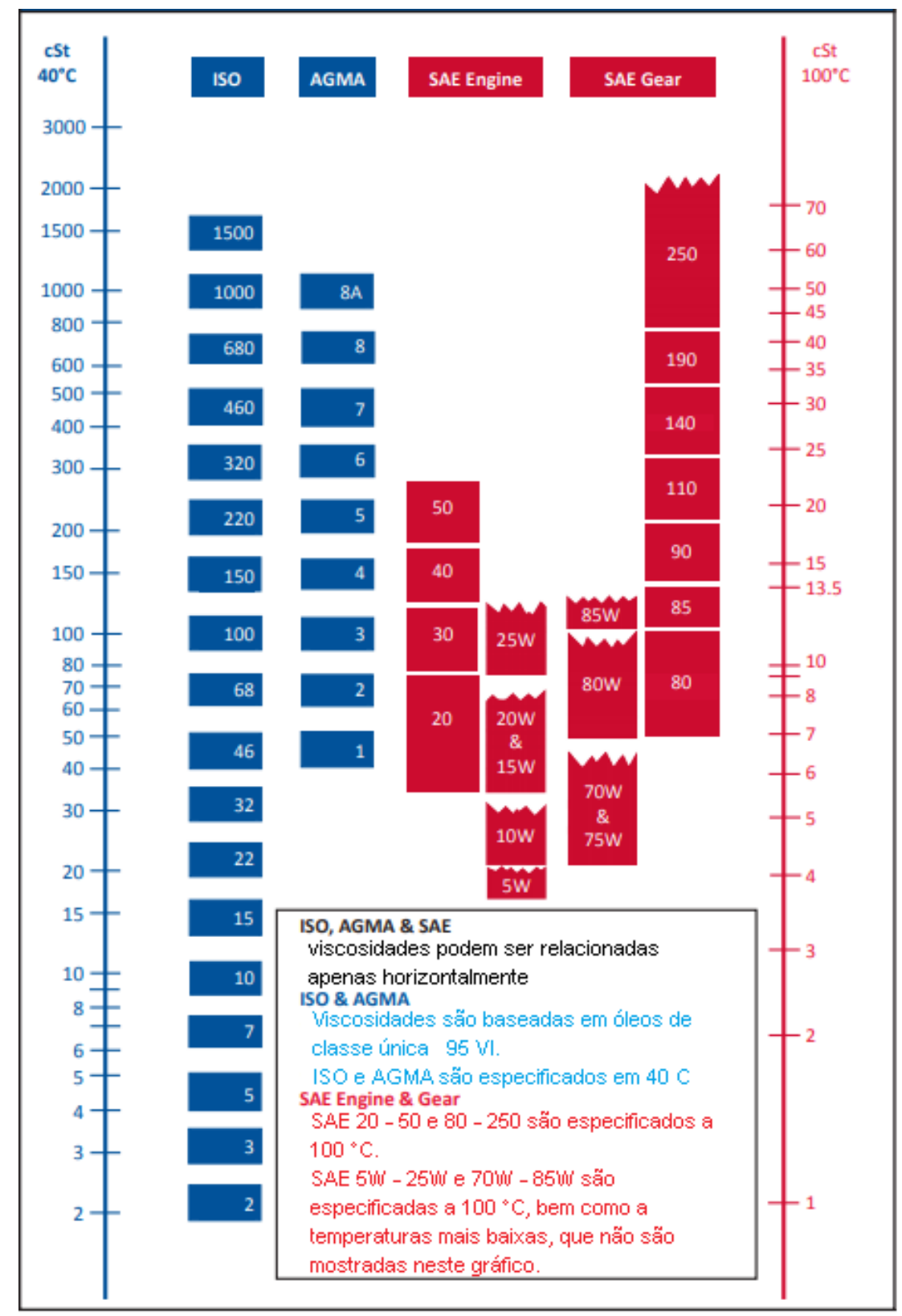

Figura 23: Carta de viscosidades equivalentes entre normas SAE, ISO e AGMA (Sander, 2019)

\section{Agradecimentos:}

Este trabalho contou com a revisão de dois professores doutores da área de fenômenos de transportes. Dessa forma, reforçou o conteúdo técnico de mecânica dos fluidos, especificamente na parte de lubrificantes.

Sergio Dalmas. Doutor em Engenharia Mecânica link

Raquel da Cunha Ribeiro da Silva. Doutora em Engenharia Mecânica link 


\section{Referências}

Machine design: an integrated approach. (2011).

OntoProg: An ontology-based model for implementing Prognostics Health Management in mechanical machines. (2018). Advanced Engineering Informatics, 38, 746-759. https: //doi.org/10.1016/j.aei.2018.10.006

Analise de mancais hidrodinamicos em rotores sob instabilidade fluido-induzida. (2007). [PhD thesis, Unicamp]. http://repositorio.unicamp.br/bitstream/REPOSIP/ 264101/1/Castro_HelioFioride_D.pdf

Metodologia para o Cálculo dos Coeficientes Dinâmicos de Mancais Hidrodinâmicos. (2016). [PhD thesis, Universidade Federal do Rio de Janeiro]. http://www.monografias. poli.ufrj.br/monografias/monopoli10018876.pdf

Pearson (Ed.). (2013). Machine elements in mechanical design (5th ed.). Pearson.

Sons, J. W. \& (Ed.). (2011). Fundamentals of machine component design (5th ed.). John Wiley \& Sons.

McGraw-Hill (Ed.). (2014). Shigley's Mechanical Engineering Design (10th ed.). McGrawHill Education.

Mecânica dos Fluidos. (2018). In McGraw-Hill (Ed.), AMGH Editora (8th ed.). McGraw-Hill. Universidades, P. (Ed.). (2008). Mecânica dos fluidos (2nd ed.). Pearson Educación.

Modelagem Unidimensional do Regime Misto de Lubrificação Aplicada a Superfícies Texturizadas.. (2010). [PhD thesis, USP]. In Universidade de São Paulo, São Paulo. https://www.teses.usp.br/teses/disponiveis/3/3152/tde29112010-155407/publico/Dissertacao_Francisco_Jose_Profito.pdf

Engine Oil Viscosity Classification. (2015). https://www.sae.org/standards/ content/j300_201501/

Putting the Simple Back into Viscosity. (2019). Lubrication Engineers. http: //www. lelubricants.com/wp-content/uploads/pdf/news/Whiteo 20Papers/simple_viscosity.pdf 